\title{
Znaczenie wysokorozdzielczych wielowskaźnikowych (multi-proxy) badań paleoekologicznych dla geografii historycznej i historii gospodarczej*
}

\section{Mariusz Lamentowicz}

https://orcid.org/0000-0003-0429-15301

Zakład Biogeografii i Paleoekologii, Uniwersytet im. Adama Mickiewicza

\section{Monika Karpińska-Kołaczek}

https://orcid.org/0000-0002-3249-7408

Pracownia Ekologii i Monitoringu Mokradeł, Uniwersytet im. Adama Mickiewicza; Zakład Biogeografii i Paleoekologii, Uniwersytet im. Adama Mickiewicza

\section{Piotr Guzowski}

https://orcid.org/0000-0002-6494-4217

Instytut Historii i Nauk Politycznych, Uniwersytet w Białymstoku

\section{Adam Izdebski}

https://orcid.org/0000-0002-3456-54784

Instytut Historii, Uniwersytet Jagielloński; Max Planck Institute for the Science of Human History

\section{Sambor Czerwiński}

https://orcid.org/0000-0003-3422-040X

Pracownia Ekologii i Monitoringu Mokradeł, Uniwersytet im. Adama Mickiewicza; Zakład Biogeografii i Paleoekologii, Uniwersytet im. Adama Mickiewicza

\section{Katarzyna Marcisz}

https://orcid.org/0000-0003-2655-9729

Pracownia Ekologii i Monitoringu Mokradeł, Uniwersytet im. Adama Mickiewicza; Zakład Biogeografii i Paleoekologii, Uniwersytet im. Adama Mickiewicza

\section{Mariusz Gałka}

https://orcid.org/0000-0001-8906-944X

Zakład Ochrony Przyrody, Wydział Biologii i Ochrony Środowiska, Uniwersytet Łódzki

\section{Dominika Łuców}

https://orcid.org/0000-0001-9966-7478

Pracownia Ekologii i Monitoringu Mokradeł, Uniwersytet im. Adama Mickiewicza; Zakład Biogeografii i Paleoekologii, Uniwersytet im. Adama Mickiewicza

\section{Michał Słowiński}

https://orcid.org/0000-0002-3011-2682

Instytut Geografii i Przestrzennego Zagospodarowania im. Stanisława Leszczyckiego PAN

\footnotetext{
Artykuł jest efektem badań realizowanych na Wydziale Historyczno-Socjologicznym Uniwersytetu w Białymstoku w ramach kierowanego przez Piotra Guzowskiego projektu „W poszukiwaniu transdyscyplinarnej synergii: przełomy gospodarcze Polski z perspektywy historyczno-przyrodniczej na tle europejskim", finansowanego z grantu Narodowego Programu Rozwoju Humanistyki nr 2bH 15015483.
} 


\section{Piotr Kołaczek}

https://orcid.org/0000-0003-2552-8269

Pracownia Ekologii i Monitoringu Mokradeł, Uniwersytet im. Adama Mickiewicza

Zarys treści: Artykuł prezentuje znaczenie paleoekologii dla badań historii gospodarczej, geografii historycznej i historii środowiskowej. Praca przybliża możliwości metodyczne paleoekologii. Zwracamy uwagę na niewykorzystany dotąd potencjał wysokorozdzielczej paleoekologii. Wykorzystując naturalne archiwa (osady jezior i torfowisk), jesteśmy w stanie prześledzić historię przemian przyrody, możemy zrekonstruować historię i lepiej zrozumieć zmiany ekosystemów Polski oraz jej rozwój ekonomiczny.

Słowa kluczowe: paleoekologia, badania wielowskaźnikowe, badania interdyscyplinarne, geografia historyczna

\section{Wstęp}

Badania paleoekologiczne mają szerokie zastosowanie $\mathrm{w}$ rekonstruowaniu zmian klimatu i badaniu wpływu człowieka na środowisko ${ }^{1}$. Kopalne wskaźniki biotyczne (proxy), będące pozostałościami roślin i zwierząt, pozwalają na jakościowe i ilościowe rekonstrukcje zmian np. szaty roślinnej, pożarów, wylesień, eutrofizacji lub poziomu wody w różnorodnych ekosystemach $^{2}$. W przeszłości satysfakcjonujące były badania wykonywane w niskiej rozdzielczości próbkowania i datowania, jednakże postęp naukowy w ostatnich dekadach pokazał potrzebę zastosowania w badaniach paleoekologicznych wysokiej rozdzielczości. Pierwotnie wysokorozdzielcze analizy wykorzystywane były do badania zmian klimatu i zmian antropogenicznych w ostatnim millennium ${ }^{3}$.

${ }^{1}$ H.J.B. Birks, H.H. Birks, Quaternary palaeoecology, Baltimore 1980; P.C. Buckland, Peatland archaeology. A conservation resource on the edge of extinction, "Biodiversity and Conservation”, 2, 1993, s. 513-527; A.W.R. Seddon i in., Looking forward through the past. Identification of 50 priority research questions in palaeoecology, „Journal of Ecology”, 102 (1), 2014, s. 256-267.

2 Handbook of Holocene palaeoecology and palaeohydrology, ed. B.E. Berglund, Chichester-Toronto 1986.

${ }^{3} \mathrm{M}$. Lamentowicz i in., Last millennium palaeoenvironmental changes from a Baltic bog (Poland) inferred from stable isotopes, pollen,
Abstract: The article presents the importance of palaeoecology for the study of economic history, historical geography and environmental history. The text introduces the methodological possibilities of palaeoecology. We pay attention to the unused potential of high resolution palaeoecology. By using natural archives (sediments of lakes and peatlands), we are able to trace the history of changes in nature. We can reconstruct history and better understand the changes in Poland's ecosystems and its economic development.

Keywords: palaeoecology, multi-indicator studies, interdisciplinary studies, historical geography

Jakkolwiek ze względu na obecny trend promujący badania paleoklimatyczne zmiany klimatu są motywem przewodnim wielu $\operatorname{prac}^{4}$, to znaczna część z nich nie wykorzystuje potencjału interpretacyjnego w zakresie wpływu człowieka na środowisko w czasach historycznych. Badania wysokorozdzielcze są obecnie szczególnie istotne przy rekonstrukcji przemian roślinności oraz wpływu człowieka i dawnych kultur

plant macrofossils and testate amoebae, „Palaeogeography, Palaeoclimatology, Palaeoecology", 265, 2008, s. 93-106; M. Magny i in., Palaeohydrological changes and humanimpact history over the last millennium recorded at Lake Joux in the Jura Mountains, Switzerland, „The Holocene”, 18 (2), 2008, s. 255-265; F. De Vleeschouwer i in., Anthropogenic impacts in North Poland over the last 1300 years. A record of $\mathrm{Pb}, \mathrm{Zn}, \mathrm{Cu}, \mathrm{Ni}$ and $\mathrm{S}$ in an ombrotrophic peat bog, „Science of the Total Environment”, 407 (21), 2009, s. 5674-5684; W.0. van der Knaap i in., A multi-proxy, high-resolution record of peatland development and its drivers during the last millennium from the subalpine Swiss Alps, "Quaternary Science Reviews", 30 (23-24), 2011, s. 3467-3480; A. Feurdean i in., Last Millennium hydro-climate variability in Central-Eastern Europe (Northern Carpathians, Romania), „The Holocene”, 25 (7), 2015, s. 1179-1192.

${ }^{4}$ I. Larocque-Tobler i in., Thousand years of climate change reconstructed from chironomid subfossils preserved in varved lake Silvaplana, Engadine, Switzerland, „Quaternary Science Reviews”, 29 (15-16), 2010, s. 1940-1949; W.0. van der Knaap i in., A multi-proxy, high-resolution record, s. 3467-3480; W. Finsinger i in., Climate change during the past 1000 years. A high-temporal-resolution multiproxy record from a mire in northern Finland, „Journal of Quaternary Science”, 28 (2), 2013, s. 152-164. 
na szatę roślinną ${ }^{5}$, a także przy konfrontowaniu tych rekonstrukcji z danymi historycznymi i archeologicznymi ${ }^{6}$.

Silna integracja badań historycznych ze studiami paleoekologicznymi wciąż jest jednak rzadkością. Przykładem pracy

${ }^{5}$ W.0. van der Knaap, J.F.N. van Leeuwen, Climate-pollen relationships AD 1901-1996 in two small mires near the forest limit in the northern and central Swiss Alps, „The Holocene”, 13 (6), 2003, s. 809-828; D.J. Charman, Summer water deficit variability controls on peatland water-table changes. Implications for Holocene palaeoclimate reconstructions, „The Holocene”, 17 (2), 2007, s. 217-227; W. Tylmann i in., Laminated lake sediments in northeast Poland. Distribution, preconditions for formation and potential for paleoenvironmental investigation, „Journal of Paleolimnology”, 50 (4), 2013, s. 487-503; $S$. Blockley $i$ in., The resilience of postglacial hunter-gatherers to abrupt climate change, „Nat Ecol Evol”, 2 (5), 2018, s. 810-818.

${ }^{6} \mathrm{H}$. Joosten, P. De Klerk, DAMOCLES. A DAshing MOnolith Cutter for fine sectioning of peats and sediments into LargE Slices, „Boreas”, 36, 2007, s. 76-81; M.J. Amesbury, K.E. Barber, P.D.M. Hughes, The methodological basis for fine-resolution, multi-proxy reconstructions of ombrotrophic peat bog surface wetness, „Boreas”, 40 (1), 2011 s. 161-174; W.0. van der Knaap, J.F.N. van Leeuwen, Climate-pollen relationships, s. 809-828; D.J. Charman, Summer water deficit variability controls, s. 217-227; W. Tylmann i in., Laminated lake sediments, s. 487-503; S. Blockley i in., The resilience of postglacial hunter-gatherers, s. 810-818.

T.J. Sloan i in., Peatland afforestation in the UK and consequences for carbon storage, „Mires and Peat”, 23, 2008; M. Latałowa, M. Badura, J. Jarosińska, Archaeobotanical samples from non-specific urban contexts as a tool for reconstructing environmental conditions (examples from Elbląg and Kotobrzeg, northern Poland), ,Vegetation History and Archaeobotany", 12 (2), 2003, s. 93-104; A. Brown, A. Pluskowski, Detecting the environmental impact of the Baltic Crusades on a late-medieval $\left(13^{\text {th }}-15^{\text {th }}\right.$ century) frontier landscape. Palynological analysis from Malbork Castle and hinterland, Northern Poland, „Journal of Archaeological Science”, 38 (8), 2011, s. 1957-1966; ciż, Medieval landscape transformation in the southeast and eastern Baltic. Palaeoenvironmental perspectives on the colonisation of frontier landscapes, „Archaeologia Baltica”, 20, 2014; P. Kittel i in., A multi-proxy reconstruction from Lutomiersk-Koziówki, Central Poland, in the context of early modern hemp and flax processing, ,Journal of Archaeological Science", 2014, 50, 2014, s. 318-337; A. Brown $\mathrm{i}$ in., The ecological impact of conquest and colonization on a medieval frontier landscape. Combined palynological and geochemical analysis of lake sediments from Radzyń Chełminski, northern Poland, „Geoarchaeology”, 30, 2015, s. 511-527; A. Izdebski i in., Realising consilience. How better communication between archaeologists, historians and natural scientists can transform the study of past climate change in the Mediterranean, "Quaternary Science Reviews", 136, 2016, s. 5-22; L. Sadori i in., Climate, environment and society in southern Italy during the last 2000 years. A review of the environmental, historical and archaeological evidence, "Quaternary Science Reviews", 136, 2016, s. 173-178; E. Xoplaki i in., The Medieval climate anomaly and Byzantium. A review of the evidence on climatic fluctuations, economic performance and societal change, "Quaternary Science Reviews", 136, 2016, s. 229-252; A. Brown i in., Plant macrofossil, pollen and invertebrate analysis of a mid-14 $4^{\text {th }}$ century cesspit from medieval Riga, Latvia (the eastern Baltic). Taphonomy and indicators of human diet, „Journal of Archaeological Science. Reports”, 11, 2017, łączącej paleoekologię z archeologią, choć wykonanej w niskiej rozdzielczości i bez zastosowania datowań radiowęglowych, jest opracowanie rozwoju roślinności obszaru Gniezna ${ }^{8}$. Przedstawiono tam wpływ rozwoju państwowości polskiej na otaczającą roślinność i ekosystem jeziora ${ }^{9}$, czego skutkiem były wylesienia i znacząca transformacja krajobrazu. Stosunkowo najczęściej spotykane są prace łączące badania archeologiczne z paleobotanicznymi analizą palinologiczną i analizą szczątków makroskopowych ${ }^{10}$.

Niniejszy artykuł ma na celu zwarte zaprezentowanie znaczenia paleoekologii dla badań historycznych, ze szczególnym uwzględnieniem historii gospodarczej, geografii historycznej i historii środowiskowej. Zwracamy uwagę na niewykorzystany dotąd potencjał wysokorozdzielczych analiz paleoekologicznych w interdyscyplinarnych badaniach nad zmianami środowiska w czasach historycznych ${ }^{11}$. Jednocześnie sugerujemy, jaki standard powinny mieć dane paleoekologiczne, żeby mogły stanowić istotne wsparcie dla interpretacji historycznych.

s. 674-682; M. Słowiński i in., Paleoecological and historical data as an important tool in ecosystem management, „Journal of Environmental Management", 236, 2019, s. 755-768.

${ }^{8}$ M. Makohonienko, Przyrodnicza historia Gniezna, Poznań-Bydgoszcz 2000 (Prace Zakładu Biogeografii i Paleoekologii).

${ }^{9}$ Tamże.

${ }^{10}$ P.C. Buckland, Peatland archaeology, s. 513-527; R.C. Chiverrell $\mathrm{i}$ in., Palaeoecological and archaeological evidence for Bronze Age human activity on the Isle of Man, „The Holocene”, 14 (3), 2004, s. 346-360; B.R. Gearey, C.J. Caseldine, Archaeological applications of testate amoebae analyses. A case study from Derryville, Co. Tipperary, Ireland, „Journal of Archaeological Science”, 33 (1), 2005, S. 49-55; B.R. Gearey, W. Fletcher, R. Fyfe, Managing, valuing, and protecting heritage resources in the twenty-first century. Peatland archaeology, the ecosystem services framework, and the Kyoto protocol, "Conservation and Management of Archaeological Sites”, 16 (3), 2014, s. 236-244; P. Kittel i in., The palaeoecological development of the Late Medieval moat - Multiproxy research at Rozprza, Central Poland, „Quaternary International”, 52, 2019, s. 21-28; P. Kittel, J. Sikora, P. Wroniecki, A Late Medieval motte-and-bailey settlement in a lowland river valley landscape of Central Poland, "Geoarchaeology", 33 (5), 2018, s. 558-578.

${ }^{11} \mathrm{~J}$. Haldon i in., History meets palaeoscience. Consilience and collaboration in studying past societal responses to environmental change, „Proceedings of the National Academy of Sciences of the United States of America", 115 (13), 2018, s. 3210-3218. 
Torfowiska i jeziora jako archiwa przeszłości

Osady jezior i torfowisk są niezwykle istotnym archiwum zmian środowiska w przeszłości ${ }^{12}$. Dzięki badaniom osadów biogenicznych (ryc. 1) możemy się cofnąć w czasie o tysiące lat i badać zmiany przyrody oraz rozwijającą się gospodarkę człowieka mimo braku źródeł pisanych ${ }^{13}$. W osadach tych ekosystemów zakonserwowane zostały szczątki roślin (w tym roślin torfotwórczych oraz ziarna pyłku) i zwierząt, które po identyfikacji i kwantyfikacji mogą posłużyć do tworzenia ilościowych i jakościowych rekonstrukcji przekształceń przyrody dokonanych ręką człowieka lub wywołanych przez zmiany klimatu.

Torf (ryc. 1B) to nierozłożona materia organiczna ${ }^{14}$, która przechowuje informację o zmianach roślinności, hydrologii oraz wpływie człowieka ${ }^{15}$. Akumuluje się on in situ i dobrze konserwuje mikrofosylia, tj. pyłek ${ }^{16}$, ameby skorupkowe ${ }^{17}$, makroszczątki roślinne ${ }^{18}$, ale także ludzkie

${ }^{12}$ K. Tobolski, Przewodnik do oznaczania torfów i osadów jeziornych,
Warszawa 2000.

${ }^{13}$ H.J.B. Birks, H.H. Birks, Quaternary palaeoecology; B. Aaby, Palaeoecological studies of mires, w: Handbook of Holocene palaeoecology, s. 145-163; S. Żurek, Związek procesu zatorfienia z elementami środowiska przyrodniczego wschodniej Polski, „Roczniki Nauk Rolniczych", 1990, s. 1-174; K. Tobolski, Torfowiska, na przykładzie Ziemi Świeckiej, Świecie 2003; tenże, Torfowiska Parku Narodowego „Bory Tucholskie", Charzykowy 2006; C.G. Armstrong i in., Anthropological contributions to historical ecology. 50 questions, infinite prospects, „PLOS ONE”, 12, 2017, s. 1-26.

${ }^{14}$ S. Kulczyński, Torfowiska Polesia, t. 1, Kraków 1939 (Prace Rolniczo-Leśne, 37); tenże, Torfowiska Polesia, t. 2, Kraków 1940 (Prace Rolniczo-Leśne, 37), s. 395-777; M. Lamentowicz i in., Z wody ląd, czyli jak z jezior powstają torfowiska, w: Udostępnianie zasobów przyrodniczych Borów Tucholskich poprzez aktywną edukację ekologiczną. Materiały na konferencję naukową 21.11.2003, Charzykowy 2003, s. 106-113.

${ }^{15} \mathrm{P}$. Lageras, A commissioned archaeology in wetlands. Experience from the E4 project in Skane, Southern Sweden, „European Journal of Archaeology", 6, 2003, s. 231-249.

${ }^{16}$ B.E. Berglund, M. Ralska-Jasiewiczowa, Pollen analysis and pollen diagrams, w: Handbook of Holocene paleoecology, s. 455-484.

${ }^{17}$ E.A.D. Mitchell, D.J. Charman, B.G. Warner, Testate amoebae analysis in ecological and paleoecological studies of wetlands. Past, present and future, „Biodiversity and Conservation”, 17, 2007, s. 2115-2137.

${ }^{18}$ D. Mauquoy, B. van Geel, Mire and peat macros, w: Encyclopedia of quaternary science, vol. 3: Pal-Pol, ed. S.A. Elias, Amsterdam 2007; M. Gałka i in., Palaeohydrology, fires and vegetation succession in the southern Baltic during the last 7500 years reconstructed from a raised bog based on multi-proxy data, „Palaeogeography, Palaeoclimatology, Palaeoecology", 370, 2013, s. 209-221. zwłoki ${ }^{19}$ lub artefakty archeologiczne ${ }^{20}$. Jednym z najbardziej spektakularnych przykładów wykorzystania torfowisk w archeologii są badania prowadzone na stanowisku w Biskupinie, gdzie pod warstwami torfu odkryto pozostałości osady z przełomu epok brązu i żelaza ${ }^{21}$. Odnajdywanie podobnych stanowisk w Europie i na świecie doprowadziło do powstania odrębnej dyscypliny - archeologii mokradłowej (ang. wetland archaeology), która bada ślady pozostawione w torfowiskach i jeziorach ${ }^{22}$.

Zmiany środowiska możemy też szczegółowo zrekonstruować dzięki gytiom, czyli osadom jeziornym (ryc. 1C, 1D) ${ }^{23}$, które powstają na skutek osadzania się materii organicznej i mineralnej na dnie zbiornika wodnego. W przeciwieństwie do torfu komponenty gytii pochodzą zwykle spoza miejsca akumulacji ${ }^{24}$. Znajdziemy tam duże bogactwo mikrofosyliów (np. pyłki, makroszczątki roślinne, szczątki larw ochotkowatych), które mogą dostarczyć informacji o środowisku i klimacie w przeszłości.

Duże rozdzielczości próbkowania osadów biogenicznych wynikają z obiektywnej chęci wykonania wysokiej rozdzielczości analiz ${ }^{25}$ lub z charakteru osadów,

${ }^{19} \mathrm{G}$. Turner-Walker, E.E. Peacock, Preliminary results of bone diagenesis in Scandinavian bogs, „Palaeogeography, Palaeoclimatology, Palaeoecology", 266, 2008, s. 151-159; D.M. Wilkinson, H.J. 0'Regan, T. Clare, Where are the non-human bog bodies?, „Journal of Wetland Archaeology", 6 (1), 2006, s. 99-104.

${ }^{20}$ A. Lageras, A commissioned archaeology, s. 231-249; B.R. Gearey, G. Fletcher, R. Fyfe, Managing, s. 236-244.

${ }^{21} \mathrm{~J}$. Kostrzewski, Osada bagienna w Biskupinie w pow. żnińskim = Un village fortifiée sur le marais du premier âge du fer, découvert à Biskupin (Grande Pologne), „Przegląd Archeologiczny”, 5 (2-3), 1936, s. 121-140; K. Dzięgielewski, The past societies. The rise and fall of Biskupin and its counterparts, Warsaw 2017.

${ }^{22}$ P.C. Buckland, Peatland archaeology, s. 513-527; M. Gowen i in., Wetland and landscape archaeology in County Tipperary. The Lisheen Archaeological Project, 2000; P. Lageras, A commissioned archaeology, s. 231-249.

${ }^{23}$ M. Ralska-Jasiewiczowa i in., Lake Gościąż, Central Poland. A monographic study, vol. 1, Kraków 1998.

${ }^{24}$ K. Tobolski, Przewodnik.

${ }^{25}$ M. Gałka, K. Apolinarska, Climate change, vegetation development, and lake level fluctuations in Lake Purwin (NE Poland) during the last $8600 \mathrm{cal}$. BP based on a high-resolution plant macrofossil record and stable isotope data ( $\delta 13 \mathrm{C}$ and $\delta 180$ ), ,Quaternary International”, 328-329, 2014, s. 213-225. 
A

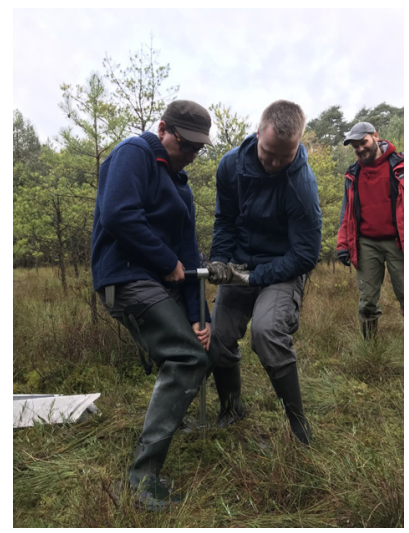

B

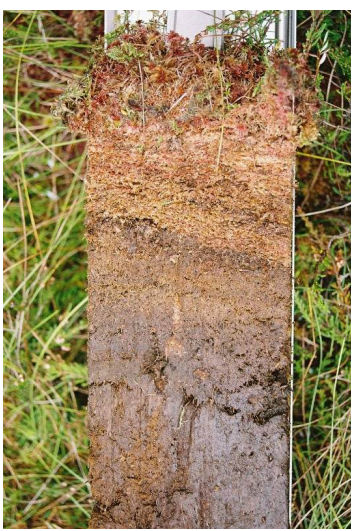

C

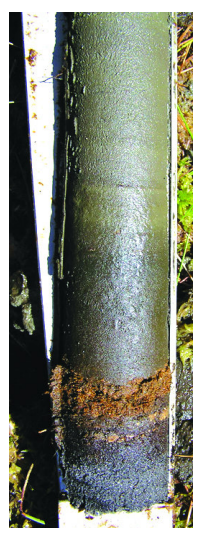

D

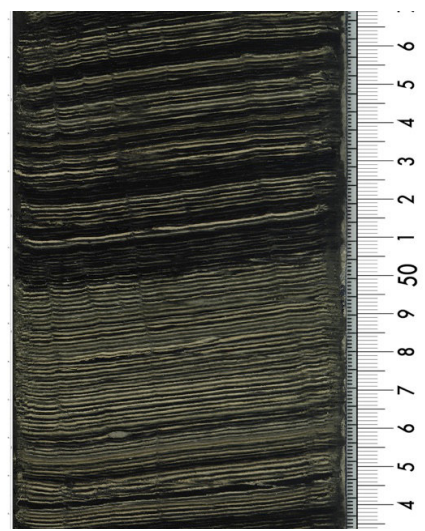

Ryc. 1. Prace terenowe na torfowisku - pobieranie rdzenia torfowego.

A) Wiercenia na torfowisku Święte k. Przemętu; B) monolit torfowy - rezultat pobierania materiału próbnikiem Wardenaar;

C) osad jeziorny (gytia) z torfem bazalnym; D) jeziorne osady laminowane (fot. M. Słowiński)

które wymuszają strategię badań wysokiej rozdzielczości, czego przykładem są jeziorne osady laminowane ${ }^{26}$. Lamina to pojedyncza dająca się rozróżnić makro- lub mikroskopowo warstwa będąca rezultatem depozycji w określonym czasie, najczęściej sezonie lub półroczu ${ }^{27}$. Laminy jeziorne są bardzo precyzyjnym źródłem informacji pod względem rozdzielczości czasowej ${ }^{28}$. Dzięki temu, że każda lamina osadu reprezentuje jeden rok, możliwe jest dokładne określenie wieku takich wydarzeń historycznych jak wylesienia, pożary lub początki osadnictwa ${ }^{29}$.

Torfowiska i jeziora dostarczają zatem komplementarnych informacji zapisanych w osadach organicznych, a jednak

\footnotetext{
${ }^{26}$ B. Zolitschka i in., Varves in lake sediments - a review, „Quaternary Science Reviews", 117, 2015, s. 1-41.

${ }^{27}$ W. Tylmann, Jeziorne osady rocznie laminowane w pótnocnej Polsce. Aktualny stan rozpoznania, postępy metodyczne i perspektywy badawcze, „Studia Limnologica et Telmatologica”, 5 (1), 2011, s. 23-41.

${ }^{28} \mathrm{~T}$. Goslar i in., Anthropogenic changes in the sediment composition of Lake Gościąż (central Poland), during the last 330 yrs, „Journal of Paleolimnology", 22, 1999, s. 171-185; W. Tylmann i in., Multiple dating of varved sediments from Lake Lazduny, northern Poland. Toward an improved chronology for the last 150 years, "Quaternary Geochronology", 15, 2013, s. 98-107; D. Weisbrodt i in., Contribution of non-pollen palynomorphs to reconstructions of land-use changes and lake eutrophication. Case study from Lake Jaczno, northeastern Poland, „Limnological Review”, 16 (4), 2016, s. 247-256.

${ }^{29}$ W. Tylmann, Jeziorne osady, s. 23-41; M. Słowiński i in., Paleoecological and historical data, s. 755-768.
}

rzadkością są studia porównujące zapis z torfowiska i jeziora znajdujących się w bezpośrednim sąsiedztwie ${ }^{30}$. Poza wysoką rozdzielczością analiz wykorzystywanych do badań interdyscyplinarnych należy zwrócić uwagę na otrzymanie możliwie kompletnego zapisu przemian środowiska z wykorzystaniem wszystkich dostępnych archiwów przyrodniczych.

\section{Chronologia - datowania}

Ustalenie bezwzględnej chronologii osadów jest pierwszym i kluczowym krokiem w badaniach paleoekologicznych. Do porównań z danymi historycznymi na obszarze Polski wykorzystuje się głównie ostatnie 1500-1000 lat, kiedy pojawiają źródła pisane. Chronologie oparte na datowaniach w liczbie mniej niż trzy na milenium są zwykle nieprzydatne do porównywania z precyzyjnymi danymi historycznymi. Skala czasu o znacznie wyższej jakości powstaje wtedy, gdy jedna data radiowęglowa przypada na 100 lat. Oczywiście im więcej dat, tym lepiej, pod warunkiem że profil jest kompletny i nie

\footnotetext{
${ }^{30} \mathrm{M}$. Latałowa, Major aspects of the vegetational history in the eastern Baltic coastal zone of Poland (Lake Zarnowiec), „Acta Palaeobotanica”, 22 (1), 1982, s. 47-63.
} 
zawiera hiatusów (przerw w akumulacji osadu). Dzięki gęstemu datowaniu możemy jednak precyzyjnie wykrywać takie luki w osadach. W przypadku profili torfowych i osadów jeziornych nielaminowanych najbardziej rozpowszechniona jest $\mathrm{w}$ datowaniu metoda węgla ${ }^{14} \mathrm{C}$, a szczególnie technika AMS, która pozwala na bardzo precyzyjne datowanie bardzo małych fragmentów pochodzenia organicznego ${ }^{31}$. Możemy dzięki niej datować łodyżki mchów czy nasiona lub fragmenty epidermy roślin. Ponadto daty z każdego profilu podlegają obróbce statystycznej, tzw. bayesowskiemu modelowaniu wiek-głębokość ${ }^{32}$. Technika ta pozwala na statystyczne oszacowanie wiarygodnego wieku kalendarzowego dla odcinków pomiędzy dwiema datami, a tym samym skonstruowanie skali czasu dla interesującego nas odcinka. Modele wiek-głębokość mogą być wykonane w różnych aplikacjach, a najbardziej popularne to $\mathrm{OxCa}^{33}$ lub działający w środowisku statystycznym $\mathrm{R}$ rbacon ${ }^{34}$. Rycina 2 pokazuje niskiej (A) i wysokiej (B) jakości model wiek-głębokość. Określenie wieku każdej dodatkowej próbki badanego profilu znacznie podnosi możliwość uzyskania wiernej (ang. robust) skali czasu ${ }^{35}$. Jak pokazują ostatnie badania, modelowanie bayesowskie i jak największa liczba dat są niezbędne do uzyskania wysokiej jakości

\footnotetext{
${ }^{31}$ M.R. Kilian, J. van der Plicht, B. Van Geel, Dating raised bogs. New aspects of $A M S^{14} \mathrm{C}$ wiggle matching, a reservoir effect and climatic change, "Quaternary Science Reviews", 14, 1995, s. 959-966; M.E. Goodsite i in., High-resolution AMS ${ }^{14} \mathrm{C}$ dating of post-bomb peat archives of atmospheric pollutants, „Radiocarbon”, 43 (2B), 2001, s. 495-515; A. Walanus, T. Goslar, Datowanie radiowęglowe, Kraków 2009.

${ }^{32} \mathrm{~A}$. Walanus, T. Goslar, Wyznaczanie wieku metodą ${ }^{14} \mathrm{C}$ dla archeologów, Rzeszów 2004

${ }^{33}$ Ch. Bronk Ramsey, Radiocarbon calibration and analysis of stratigraphy. The 0xCal program, „Radiocarbon”, 37 (2), 1995, s. 425-430; tenże, Development of the radiocarbon program OxCal, „Radiocarbon”, 43 (2A), 2001, s. 355-363; tenże, Deposition models for chronological records, „Quaternary Science Reviews”, 27 (1-2), 2008, s. 42-60.

${ }^{34}$ M. Blaauw, J.A. Christen, Flexible paleoclimate age-depth models using an autoregressive gamma process, „Bayesian Analysis”, 6 (3), 2011, s. 457-474.

${ }^{35} \mathrm{P}$. Kołaczek i in., Increased radiocarbon dating resolution of ombrotrophic peat profiles reveals periods of disturbance which were previously undetected, „Quaternary Geochronology”, 52, 2019, s. 21-28.
}

chronologii radiowęglowych ${ }^{36}$. Dotyczy to także datowania za pomocą izotopu ołowiu ${ }^{210} \mathrm{~Pb}$, które może podnosić jakość modelowania wieku w oparciu o daty radiowęglowe, szczególnie w odniesieniu do ostatnich 120 lat (jest to maksymalny zasięg metody $\left.{ }^{210} \mathrm{~Pb}\right)^{37}$.

\section{Rekonstrukcje roślinności - analiza pyłkowa}

Analiza pyłkowa pozwala na odtworzenie zmian roślinności na podstawie zmian stosunku poszczególnych typów pyłku i zarodników roślin w poziomach osadów jeziornych i torfów. Z punktu widzenia badań historycznych najbardziej istotne będą rośliny uprawne oraz gatunki pośrednio związane z gospodarką człowieka i rozwojem rolnictwa, np. występujące przy siedliskach ruderalnych i pastwiskach oraz chwasty ${ }^{38}$. Ważnym aspektem jest również identyfikacja wylesień powodowanych wzrostem aktywności gospodarczej człowieka ${ }^{39}$.

W standardzie badań o wysokiej rozdzielczości każdy pobrany rdzeń zostaje pocięty na fragmenty o miąższości 1 lub nawet $0,2 \mathrm{~cm}$ (ryc. 3$)^{40}$. Z każdego z takich plastrów pobiera się próbę do analizy palinologicznej. Analiza wykonana z ciagłym próbkowaniem jest niesłychanie istotna dla zrozumienia krótkoterminowych zmian roślinności związanych z takimi procesami jak wyludnienia spowodowane wojnami

\footnotetext{
${ }^{36} \mathrm{M}$. Blaauw i in., Double the dates and go for Bayes. Impacts of model choice, dating density and quality on chronologies, "Quaternary Science Reviews", 188, 2018, s. 58-66.

${ }^{37}$ M.A. Aquino-López i in., Bayesian analysis of ${ }^{210} \mathrm{~Pb}$ dating, ,Journal of Agricultural, Biological and Environmental Statistics", 23 (3), 2018, s. 317-333.

${ }^{38} \mathrm{~K}$.-E. Behre, The interpretation of anthopogenic indicators in pollen diagrams, „Pollen and Spores”, 23, 1981, s. 225-245; T. Giesecke i in., Towards mapping the late Quaternary vegetation change of Europe, „Vegetation History and Archaeobotany”, 23 (1), 2013, s. 75-86.

${ }^{39}$ C.N. French, P.D. Moore, Deforestation, cannabis cultivation and Schwingmoor formation at Cors Llyn (Llyn Mire), Central Wales, ,New Phytologist", 102 (3), 1986, s. 469-482; J.0. Kaplan, K.M. Krumhardt, N. Zimmermann, The prehistoric and preindustrial deforestation of Europe, „Quaternary Science Reviews”, 28 (27-28), s. 3016-3034.

${ }^{40} \mathrm{C}$. Kamenik i in., Pollen/climate calibration based on a near-annual peat sequence from the Swiss Alps, „Journal of Quaternary Science”, 24 (5), 2009, s. 529-546.
} 


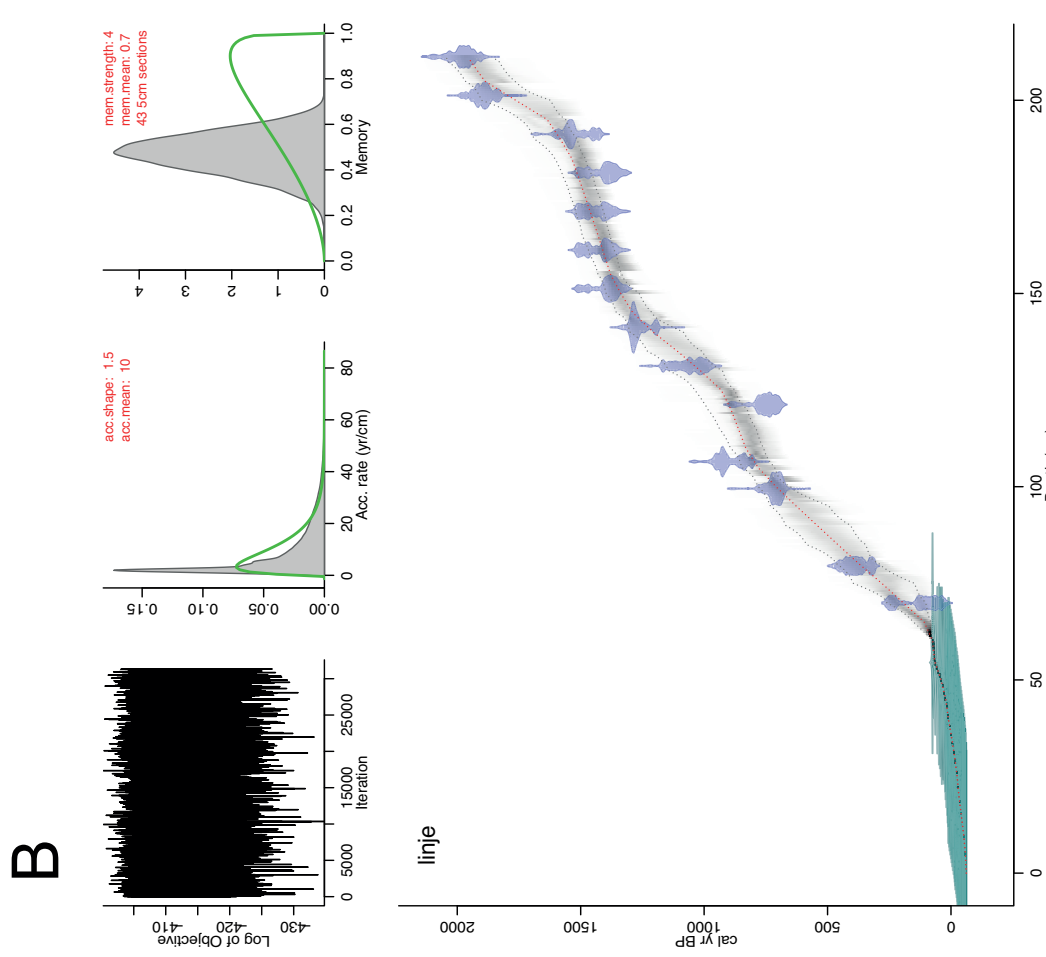



న్తి

స్తి

空

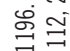

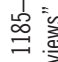

is

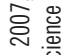

ô

I

잉

음
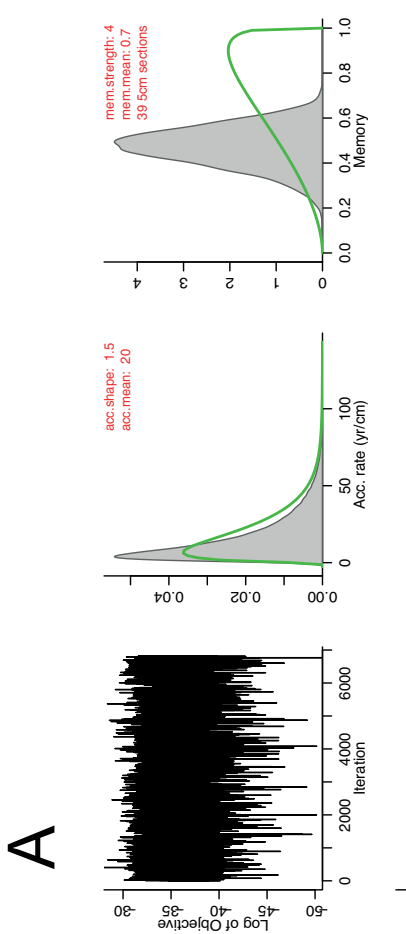

ब्ञ

ఫิ

范

곤

ํำ

ฐิ

을

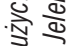

N

ড় 는

हิ है

혼

究

s 웡

क क.

证

ㅎํㄴ 온

बi

क人

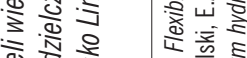



ह. के

高

촌응

두워

넌 

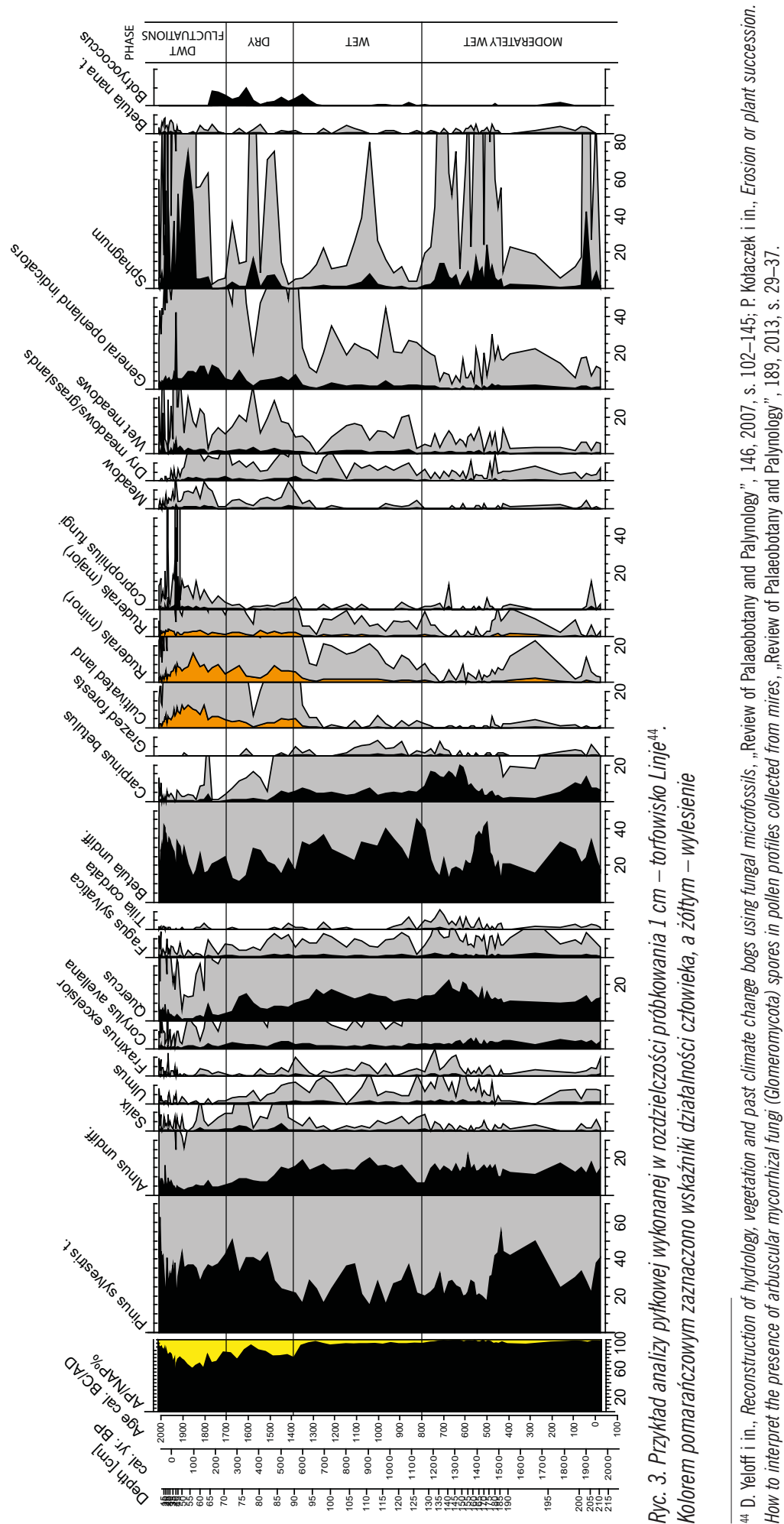
czy epidemiami chorób, np. czarnej śmier$\mathrm{ci}^{45}$. Próby osadów przeznaczone do analizy palinologicznej poddawane są standardowej obróbce laboratoryjnej ${ }^{46}$. Z odpowiednio przygotowanych prób wykonuje się preparaty mikroskopowe, w których oznaczane i zliczane są wszystkie możliwe typy pyłków i zarodniki. Przy oznaczeniach typów pyłkowych użyteczne są specjalistyczne atlasy ${ }^{47}$.

\section{Wpływ człowieka - palinomorfy niepyłkowe}

Bardzo ważną rolę w identyfikowaniu obecności człowieka odgrywa analiza palinomorf niepyłkowych (ang. non-pollen palynomorphs, NPP), którą wykonuje się równolegle $\mathrm{z}$ analizą pyłkową. Palinomorfy niepyłkowe to niejednorodna grupa mikrofosyliów, do której zaliczamy glony, cyjanobakterie, zarodniki grzybów, fragmenty tkanek roślinnych, szczątków zwierzęcych i inne struktury organiczne niebędące pyłkiem, a znajdujące się w próbach do analizy palinologicznej. Z punktu widzenia badań nad wpływem człowieka na środowisko duże znaczenie mają grzyby koprofilne, tj. występujące na odchodach ${ }^{48}$. Wzmożone użytkowanie zlewni jezior i torfowisk, jak i samych torfowisk w celach pasterskich powinno być rejestrowane w postaci zwiększonego występowania tego typu grzybów ${ }^{49}$. Można dzięki temu wnioskować o wypasie zwierząt i zintensyfi-

\footnotetext{
${ }^{45}$ B.V. Schmid i in., Climate-driven introduction of the Black Death and successive plague reintroductions into Europe, „Proceedings of the National Academy of Sciences", 112 (10), 2015, s. 3020-3025; L. Sadori i in., Climate, s. 173-188.

${ }^{46}$ B.E. Berglund, M. Ralska-Jasiewiczowa, Pollen analysis, s. 455-484

${ }^{47}$ H.J. Beug, Leitfaden der Pollenbestimmung für Mitteleuropa und angrenzende Gebiete, München 2004; P.D Moore, J.A. Webb, M.E. Collinson, Pollen analysis, Oxford 1991.

${ }^{48} \mathrm{D}$. Yeloff i in., Reconstruction of hydrology, vegetation and past climate change bogs using fungal microfossils, , Review of Palaeobotany and Palynology", 146, 2007, s. 102-145; P. Kołaczek i in., Erosion or plant succession. How to interpret the presence of arbuscular mycorrhizal fungi (Glomeromycota) spores in pollen profiles collected from mires, „Review of Palaeobotany and Palynology”, 189, 2013, s. 29-37.

${ }^{49}$ B. van Geel, Non-pollen palynomorphs, w: Tracking environmental change using lake sediments, vol. 3: Terrestrial, algal and siliceous indicators, ed. J.P. Smol, H.J.B. Birks, W.M. Last, Dordrecht-BostonLondon 2002, s. 99-119.
}

kowanym wpływie człowieka. Jeszcze dokładniejszych informacji dostarcza obecność jaj pasożytów, takich jak glista ludzka (Ascaris sp.) czy włosogłówka (Trichuris sp.), które świadczą o obecności człowieka lub zwierzat gospodarskich i domowych ${ }^{50}$. Palinomorfy dostarczają też pośrednich dowodów wpływu człowieka na środowisko. Mogą być przydatne w identyfikacji zmian hydrologicznych (osuszania torfowisk pod miejsca na uprawy lub wypas) czy intensywniejszej gospodarki człowieka (eutrofizacji jezior $)^{51}$. Metodyka laboratoryjna i analiza prób w przypadku palinomorf niepyłkowych jest taka sama, jak przy standardowej analizie palinologicznej. Palinomorfy niepyłkowe identyfikowane są na podstawie dostępnej literatury przedmiotu ${ }^{52}$.

\section{Rekonstrukcje roślinności lokalnej - makroszczątki roślinne}

Makroszczątki roślinne mają szerokie zastosowanie w badaniu zmian środowiska w przeszłości. W szczególności wykorzystuje się je w badaniach archeobotanicznych, gdyż pozwalają odpowiedzieć na pytania dotyczące rozwoju rolnictwa i roślinnych składników diety ${ }^{53}$. Analiza makroszczątkowa $\mathrm{z}$ rdzeni torfowych lub jeziornych dostarcza też jednak innych informacji -

\footnotetext{
${ }^{50}$ 0. Brinkkemper, H. van Haaster, Eggs of intestinal parasites whipworm (Trichuris) and mawworm (Ascaris): Non-pollen palynomorphs in archaeological samples, „Review of Palaeobotany and Palynology”, 186, 2012, s. 16-21.

${ }^{51}$ P. Kołaczek i in., Interplay of climate-human-vegetation on the north-eastern edge of the Carpathians (Western Ukraine) between 7500 and 3500 calibrated years $B P$, .,Biological Journal of the Linnean Society", 119 (3), 2016, s. 609-629.

${ }^{52} \mathrm{~A}$. Miola, Tools for non-pollen palynomorphs (NPPS) analysis. A list of Quaternary NPP types and reference literature in English language (1972-2011), „Review of Palaeobotany and Palynology”, 186, 2012, s. $142-161$.

${ }^{53}$ M. Latałowa, Botanical analysis of a bundle of flax (Linum usitatissimum L.) from an early medieval site in northern Poland; a contribution to the history of flax cultivation and its field weeds, ,Vegetation History and Archaeobotany", 7 (2), 1998, s. 97-107; M. Lityńska-Zając, K. Wasylikowa, Przewodnik do badań archeobotanicznych, Poznań 2005; M. Badura, M. Latałowa, Szczątki makroskopowe roślin z obiektów archeologicznych Zespołu Przedbramia w Gdańsku, w: Zespót Przedbramia ul. Długiej w Gdańsku. Studium archeologiczne, Gdańsk 2016, s. 231-247; K. Cywa, Trees and shrubs used in medieval Poland for making everyday objects, "Vegetation History and Archaeobotany", 27, 2018, s. 111-136
} 
możliwa jest ocena składu gatunkowego roślinności torfotwórczej i jeziornej, a jednocześnie jakościowa estymacja wahań poziomu wody i zmian w dostawie materii mineralnej z otoczenia na torfowisko lub do jeziora. Analiza makroszczątków roślinnych informuje też o obecności poszczególnych gatunków roślin w miejscu ich występowania, a w przypadku jezior także tych, które zostały dostarczone z bliskiego otoczenia. Dzięki temu analizujemy również rośliny nie zawsze mające bezpośredni kontakt z człowiekiem i otrzymujemy informacje o przekształceniach środowiska odzwierciedlających się w zmianie składu botanicznego poszczególnych prób. $\mathrm{Ma}$ kroszczątki roślinne mogą być ilościowym proxy różnych zmiennych i można zbudować z nich zbiory kalibracyjne ${ }^{54}$, ale najczęściej efektem analizy są jakościowe rekonstrukcje nawiązujące do współczesnych wymagań gatunków roślin ${ }^{55}$.

Metodyka przygotowania prób i ich analizy opisywana była w wielu podręczni$\mathrm{kach}^{56}$. Szczególnie wartościowe są analizy

${ }^{54}$ J.A. Janssens, A quantitative method for stratigraphic analysis of bryophytes in Holocene peat, „Journal of Ecology”, 71, 1983, s. 189-196; M. Väliranta i in., Reconstructing peatland water tables using transfer functions for plant macrofossils and testate amoebae. A methodological comparison, „Quaternary International”, 268, 2012, s. 34-43.

${ }^{55}$ D. Mauquoy, K.E. Barber, A replicated 3000 yr proxy-climate record from Coom Rigg Moss and Felecia Moss, the Border Mires, northern England, „Journal of Quarternary Science”, 14 (3), 1999, s. 263-275; D. Mauquoy i in., Evidence from northwest European bogs shows 'Little Ice Age' climatic changes driven by variations in solar activity, „The Holocene", 12 (1), 2002, s. 1-6; P.D.M. Hughes, K.E. Barber, Mire development across the fen-bog transition on the Teifi floodplain at Tregaron Bog, Ceredigion, Wales, and a comparison with 13 other raised bogs, ,Journal of Ecology”, 91 (2), 2003, s. 253-264; J. Loisel, Z. Yu, Surface vegetation patterning controls carbon accumulation in peatlands, „Geophysical Research Letters”, 40 (20), 2013, s. 5508-5513; M. Gałka, K. Apolinarska, Climate change, s. 213-225; M. Gatka i in., Development of rich fen on the SE Baltic coast, Latvia, during the last 7500 years, using paleoecological proxies. Implications for plant community development and paleoclimatic research, „Wetlands”, 36 (4), 2016, s. 689-703.

${ }^{56}$ H.H. Birks, Plant macrofossils in Quaternary lake sediments, „Archiv für Hydrobiologie", 15, 1980, s. 1-60; Handbook of Holocene palaeoecology; B. Warner, Methods in Quaternary ecology, Montréal 1990 (Geoscience Canada Reprint, 5); H.J.B. Birks, H.H. Birks, Future uses of pollen analysis must include plant macrofossils, „Journal of Biogeography", 27, 2000, s. 31-35; K. Tobolski, Przewodnik; H.H. Birks, H.J.B. Birks, Reconstructing Holocene climates from pollen and plant macrofossils, w: Global change in the Holocene, wykonane w wysokiej rozdzielczości (ryc. 3). Podstawą oznaczeń jest porównanie ze zbiorem porównawczym i opisami w specjalistycznych atlasach dotyczących makroszczątków ${ }^{57}$ lub szczegółowych przewodnikach do oznaczania roślin ${ }^{58}$.

\section{Zmiany hydrologiczne - ameby skorupkowe}

Kolejną metodą stosowaną w wysokorozdzielczych badaniach paleoekologicznych jest analiza ameb skorupkowych. Są to jednokomórkowe organizmy, które wytwarzają skorupkę otaczającą komórkę - różną w przypadku różnych grup gatunków ${ }^{59}$. Występują np. w mchach, glebie oraz jeziorach ${ }^{60}$. Po śmierci organizmu skorupka deponowana jest w osadach, a najlepiej zachowuje się w gytii lub torfie ${ }^{61}$. Poszczególne gatunki występują w ściśle

ed. A. Mackay i in., London 2003, s. 342-357; H.H. Birks, The importance of plant macrofossils in the reconstruction of Lateglacial vegetation and climate. Examples from Scotland, western Norway, and Minnesota, USA, „Quaternary Science Reviews”, 22, 2003, s. 453-473; D. Mauquoy, B. van Geel, Mire and peat macros; D. Mauquoy i in., A protocol for plant macrofossil analysis of peat deposits, „Mires and Peat", 7, 2010, s. 1-5.

${ }^{57}$ Н.Я. Кац, С.В. Кац, М.Г. Кипиани, Атлас определитель плодов и семян встречающихся в четвертичных отложениях СССР, Москва 1965; G. Grosse-Brauckmann, Einige allgemeine Ergebnisse von Torf-Großrestuntersuchungen, „Telma”, 5, 1975, s. 39-42; Н.Я. Кац, С.В. Кац, Е.И. Скобеева, Атлас растительных остатков в торфах, Москва 1977; G. Grosse-Brauckmann, Analysis of vegetative plant macrofossils, w: Handbook of Holocene palaeoecology, s. 591-618; G. Grosse-Brauckmann, B. Streitz, Über pflanzliche makrofossilien mitteleuropäischer Torfe. III. Früchte und Samen, Moose und einige Gewerbe (Fotos von fossilen Pflanzenresten), „Telma”, 22, 1992, s. 53-102; K. Tobolski, Przewodnik.

${ }^{58}$ B. Szafran, Mchy, t. 1, Warszawa 1957; tamże, t. 2, Warszawa 1961; G. Berggren, Atlas of seeds and small fruits of Northwest-European plant species (Sweden, Norway, Denmark, East Fennoscandia and Iceland) with morphological descriptions, part 2: Cyperaceae, Stockholm 1994; J. Landwehr, Nieuwe atlas Nederlandse bladmossen, Zutphen 1984; A.J.E. Smith, The moss flora of Britain and Ireland, Cambridge 2004; J. Laine i in., The intricate beauty of Sphagnum mosses. A Finnish guide for identification, Helsinki 2009; A. Hölzer, Die Torfmoose Südwestdeutschlands und der Nachbargebiete, Jena 2010.

${ }^{59}$ R. Meisterfeld, Order Arcellinida, Kent 1880, w: The illustrated guide to the Protozoa, ed. J.J. Lee, G.F. Leedale, P. Bradbury, Lawrence 2001, s. 827-860; tenże, Testate amoebae with filopoda, w: The illustrated guide, s. 1054-1084.

60 W. Foissner, Soil Protozoa: fundamental problems. Ecological significance, adaptations in ciliates and testaceans, bioindicators, and guide to literature, „Progress in Protistology”, 2, 1987, s. 69-212.

${ }^{61}$ D.J. Charman, D. Hendon, W.A. Woodland, The identification of testate amoebae (Protozoa: Rhizopoda) in peats. Technical guide No. 9, „Quaternary Science Reviews", 9 (9), 2000. 
określonych warunkach hydrologicznych i troficznych, dlatego stosując funkcję transferu, można je wykorzystywać jako ilościowe proxy zmian hydrologicznych w torfowiskach i jeziorach ${ }^{62}$. Dzięki współczesnym zbiorom testowym - opracowanym w Polsce np. przez Mariusza Lamentowicza i Edwarda Mitchella - możliwa jest ilościowa rekonstrukcja zmian poziomu wody (paleohydrologii) na torfowisku ${ }^{63}$ i trofii torfowiska ${ }^{64}$. Informacja ta ma niebagatelne znaczenie w przypadku interpretacji wpływu zmian klimatu na działalność człowieka w przeszłości i pozwala ustalić, czy wystąpienie tzw. suchych lub wilgotnych faz klimatycznych oddziaływało na rozwój gospodarki na obszarach, z których pobierane były rdzenie. Analiza ameb skorupkowych jest jedyną metodą, dzięki której można uzyskać obiektywną ilościową rekonstrukcję zmian poziomu wody gruntowej torfowiska. Korelacja wyników $\mathrm{z}$ analizą węgli mikro- i makroskopowych dostarcza niezwykle wartościowych informacji o zmianach klimatu i wpływie człowieka na środowisko ${ }^{65}$. W nielicznych

\footnotetext{
${ }^{62}$ M. Lamentowicz, M. Obremska, E.A.D. Mitchell, Autogenic succession, land-use change, and climatic influences on the Holocene development of a kettle-hole mire in Northern Poland, „Review of Palaeobotany and Palynology", 151 (1-2), 2008, s. 21-40; M. Lamentowicz, E.A.D. Mitchell, The ecology of testate amoebae (Protists) in Sphagnum in north-western Poland in relation to peatland ecology, "Microbial Ecology", 50 (1), 2005, s. 48-63.

${ }^{63}$ R.K. Booth, Testate amoebae as paleoindicators of surface-moisture changes on Michigan peatlands. Modern ecology and hydrological calibration, „Journal of Paleolimnology”, 28, 2002, s. 329-348 M.J. Amesbury i in., Development of a new pan-European testate amoeba transfer function for reconstructing peatland palaeohydrology, "Quaternary Science Reviews", 152, 2016, s. 132-151.

${ }^{64}$ R.K. Booth, Ecology of testate amoebae (Protozoa) in two Lake Superior coastal wetlands. Implications for paleoecology and environmental monitoring, „Wetlands”, 21 (4), 2001, s. 564-576; R.K. Booth, S.T. Jackson, A high resolution record of late-Holocene moisture variability from a Michigan raised bog, USA, „The Holocene”, 13 (6), 2003, s. 863-876; G.T. Swindles, G. Plunkett, H.M. Roe, A multiproxy climate record from a raised bog in County Fermanagh, Northern Ireland. A critical examination of the link between bog surface wetness and solar variability, ,Journal of Quaternary Science”, 22 (7), 2007, s. 667-679; J. Wheeler, G.T. Swindles, B.R. Gearey, Finding Bosworth battlefield. A multiproxy palaeoenvironmental investigation of lowland sediments from Dadlington, Leicestershire, England, „Journal of Archaeological Science", 37 (7), 2010, s. 1579-1589.

${ }^{65}$ K. Marcisz i in., Long-term hydrological dynamics, s. 138-152; S. Biagioni i in., 8000 years of vegetation dynamics and environmental
}

przypadkach ameby wykorzystywane były w badaniach archeologicznych ${ }^{66}$, w większości jednak stosuje się tę metodę w badaniu zmian klimatu lub lokalnych zmian hydrologicznych związanych z wylesieniami w przeszłości (ryc. 4$)^{67}$.

Podobnie jak w przypadku poprzednich analiz ameby skorupkowe ekstrahowane są zwykle z jednocentymetrowych fragmentów profilu. Analizy dokonuje się w próbach o objętości ok. $6 \mathrm{~cm}^{3}$. Próby są przesiewane w celu odseparowania fragmentów torfu od ameb zgodnie z powszechnie stosowanymi procedurami ${ }^{68} \mathrm{i}$ zliczane do osiągnięcia 150 skorupek ameb za pomocą mikroskopu świetlnego. Identyfikacja możliwa jest dzięki specjalistycznym publikacjom naukowym oraz atlasom ${ }^{69}$.

\section{Pożary - węgle drzewne}

Ważnym elementem umożliwiającym wykrywanie działalności człowieka i zmian klimatu w ostatnich tysiącach lat jest obecność w osadach mikro-i makroskopowych węgli drzewnych, będących świadectwem aktywności pożarowej ${ }^{70}$. Badania aktywności

changes of a unique inland peat ecosystem of the Jambi Province in Central Sumatra, Indonesia, „Palaeogeography, Palaeoclimatology, Palaeoecology", 440, 2015, s. 813-829; K. Kajukalo i in., Abrupt ecological changes in the last 800 years inferred from a mountainous bog using testate amoebae traits and multi-proxy data, „European Journal of Protistology", 55, 2016, s. 165-180.

${ }^{66}$ E.A.D. Mitchell, R. Payne, Testate amoeba analysis, „The Encyclopedia of Archaeological Sciences", 2019, s. 1-4.

${ }^{67}$ M. Lamentowicz i in., A 1300 years multi-proxy, high-resolution record from a rich fen in northern Poland. Reconstructing hydrology, land-use and climate change, „Journal of Quarternary Science”, 28 (6), 2013, s. 582-594.

${ }^{68}$ R.K. Booth, M. Lamentowicz, D.J. Charman, Preparation and analysis of testate amoebae in peatland paleoenvironmental studies, „Mires and Peat", 7 (11), 2010, s. 1-7.

${ }^{69}$ T. Grospietsch, Wechseltierchen (Rhizopoden), Stuttgart 1958; J. Charman, The identification; K.J. Clarke, Guide to identification of soil Protozoa - testate amoebae, „Soil Biodiversity Programme Research Report", 4, 2003, s. 1-40; Y. Mazei, A.N. Tsyganov, Freshwater testate amoebae, Moscow 2006.

${ }^{70} \mathrm{C}$. Whitlock, C. Larsen, Charcoal as a fire proxy, w: Tracking environmental change, s. 75-97; C. Whitlock i in., Land-use history as a guide for forest conservation and management, "Conservation Biology", 31 (1), 2017, s. 84-97; E. Dietze i in., Holocene fire activity during low-natural flammability periods reveals scale-dependent cultural human-fire relationships in Europe, "Quaternary Science Reviews", 201, 2018, s. 44-56; M. Słowiński i in., Paleoecological and historical data, s. 755-768. 







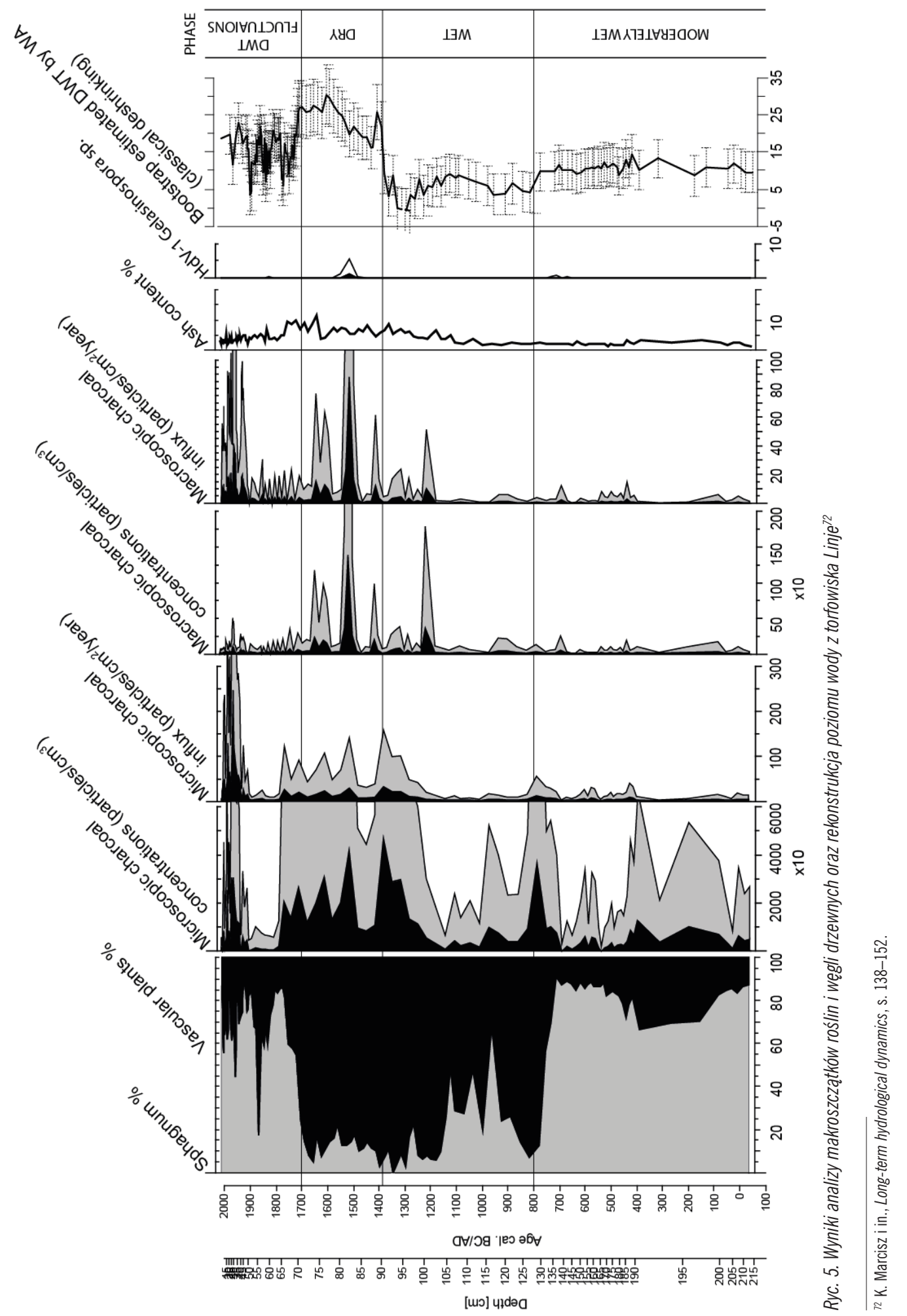

42 Studia Geohistorica • Nr 07. 2019 
pożarów stają się coraz bardziej popularne w Polsce ze względu na niemal zupełny brak danych na ten temat ${ }^{73}$. Dotyczy to szczególnie ilościowych rekonstrukcji intensywności pożarów oraz ich powierzchni (ryc. 5$)^{74}$.

Wzniecając pożary w celu usunięcia lasu, człowiek uzyskiwał nowe tereny pod uprawy, co powodowało wzrost akumulacji cząsteczek węgla w torfie i osadach ${ }^{75}$. Co więcej, zwiększenie gęstości osadnictwa sprawiało, że same domostwa stawały się silnymi emiterami tego typu cząsteczek. Dobrym wskaźnikiem zmian w strukturze pożarów w regionie są znajdowane w próbach palinologicznych węgle mikroskopowe (cząsteczki wielkości $0,01-0,1 \mathrm{~mm})^{76}$. W każdej próbie zlicza się je do osiągnięcia wartości 200 cząsteczek łącznie ze zliczanym markerem koncentracji dodanym do każdej próby ${ }^{77}$.

W przypadku węgli makroskopowych możliwa jest rekonstrukcja pożarów na samym torfowisku lub w jego najbliższym

\footnotetext{
${ }^{73}$ K. Marcisz i in., Long-term hydrological dynamics, s. 138-152. K. Marcisz i in., Synchronous fire activity and water table increases recorded from Sphagnum peatlands on the oceanic-continental climatic gradient, „Quaternary Science Reviews”, 177 (C), 2017, s. 145-157; K. Marcisz, B. Vannière, 0. Blarquez, Taking fire science and practice to the next level. Report from the PAGES Global Paleofire Working Group workshop 2017 in Montreal, Canada - paleofire knowledge for current and future ecosystem management, „Open Quaternary”, 4, 2018.

${ }^{74} \mathrm{~K}$. Marcisz i in., Responses of vegetation and testate amoeba trait composition to fire disturbances in and around a bog in central European lowlands (northern Poland), "Quaternary Science Reviews”, 208, 2019, s. 129-139; K. Kajukalo i in., Abrupt ecological changes, s. $165-180$.

${ }^{75} \mathrm{C}$. Carcaillet, A spatially precise study of Holocene fire history, climate and human impact within the Maurienne valley, North French Alps, „Journal of Ecology”, 86 (3), 1998, s. 384-396; P.A. Delcourt i in. Prehistoric human use of fire, the Eastern Agricultural Complex, and Appalachian oak-chestnut forests. Paleoecology of Cliff Palace Pond, Kentucky, „American Antiquity”, 63 (2), 1998, s. 263-278; A.L. Daniau, F. d'Errico, M.F. Sanchez Goni, Testing the hypothesis of fire use for ecosystem management by neanderthal and upper palaeolithic modern human populations, „PLOS ONE”, 5 (2), 2010, e9157; J. Kaal i in., Long-term deforestation in NW Spain. Linking the Holocene fire history to vegetation change and human activities, „Quaternary Science Reviews”, 30 (1-2), 2011, s. 161-175.

${ }^{76} \mathrm{C}$. Whitlock, C. Larsen, Charcoal, s. 75-97.

${ }^{77}$ W. Tinner, F.S. Hu, Size parameters, size-class distribution and area-number relationship of microscopic charcoal. Relevance for fire reconstruction, „The Holocene”, 13 (4), 2003, s. 499-505.
}

otoczeniu $^{78}$. Kilka stanowisk w Polsce przeanalizowano już pod tym kątem w wysokiej rozdzielczości ${ }^{79}$. W jednym ze stanowisk koło Szczecinka wykazano silny związek pomiędzy intensywnością pożarów zarejestrowanych w torfowisku a gwałtownymi przemianami społecznymi w ciągu ostatnich 500 lat $^{80}$. Bardzo wartościowe są analizy węgli drzewnych wykonane na podstawie osadów jeziornych laminowanych rocznie (ryc. 6). Metodyka stosowana do analizy węgli makroskopowych jest inna niż w przypadku mikroskopowych. Ponieważ zwraca się tu uwagę na fragmenty węgli większe niż 0,1 mm, przypomina raczej tę stosowaną $\mathrm{w}$ analizie makroskopowych szczątków roślin ${ }^{81}$. Z każdej próby pobiera się $1 \mathrm{~cm}^{3}$ osadu, a następnie pod mikroskopem stereoskopowym separuje się z niego węgle i zlicza je.

\section{Podsumowanie}

Badania paleoekologiczne mają ogromny potencjał dla badania przełomów ekologicznych, osadnictwa, rozwoju gospodarczego czy nawet demografii historycznej ${ }^{82}$. Do tej pory wiele badań z zakresu wysokorozdzielczej paleoekologii wykonywano niezależnie od dociekań prowadzonych przez historyków ${ }^{83}$. Wciąż jednak istnieje możliwość zebrania informacji i dowiązania ich do opracowanych już wcześniej stanowisk. Jednocześnie ważne jest wyznaczenie nowych stanowisk badawczych w taki sposób, aby zaistniały jak największe możliwości syntez interdyscyplinarnych. Dotyczy to szczególnie miejsc

\footnotetext{
${ }^{78}$ C. Whitlock, C. Larsen, Charcoal, s. 75-97; C. Whitlock, R.S. Anderson, Fire history reconstructions based on sediment records from lakes and wetlands, w: Fire and climatic change in temperate ecosystems of the Western Americas, ed. T.T. Veblen i in., New York 2003, s. 3-31.

${ }^{79}$ K. Marcisz i in., Long-term hydrological dynamics, s. 138-152; K. Kajukalo i in., Abrupt ecological changes, s. 165-180; K. Marcisz i in., Synchronous fire activity, s. 145-157.

${ }^{80}$ K. Marcisz i in., Responses of vegetation, s. 129-139.

${ }^{81}$ C. Whitlock, C. Larsen, Charcoal, s. 75-97.

${ }^{82}$ A. Izdebski i in., Realising consilience, s. 5-22; J. Haldon i in., History, s. 3210-3218.

${ }^{83} \mathrm{M}$. Lamentowicz i in., Last millennium palaeoenvironmental changes, s. 93-106; K. Marcisz i in., Synchronous fire activity, s. 145-157.
} 





dobrze opisanych w źródłach historycznych (najlepiej osadnictwa o charakterze masowym), dokumentujących aktywność gospodarczą. Chodzi przede wszystkim o inwentarze dóbr, typowe dla wielkich właścicieli ziemskich - króla lub instytucji kościelnych. Rozpowszechniły się one w XVI w. i rejestrowały źródła dochodów związane z gospodarką rolno-hodowlaną, przede wszystkim areał ziemi w rękach chłopów. Rozwój folwarków i biurokracji latyfundialnej sprawił, że możemy się również dowiedzieć o dominujących uprawach w gospodarstwach dworskich, wysokości zbiorów i plonów czy pogłowiu zwierząt. Nie mniejsze znaczenie mają źródła podatkowe, które $\mathrm{w}$ przypadku XVI w. dostarczają danych o wielkości ziemi w dziedzicznym użytkowaniu chłopów czy urządzeniach protoindustrialnych, których działanie wymagało eksploatacji zasobów leśnych, jak kuźnice czy browary. W kolejnych stuleciach źródła podatkowe rejestrowały dymy (domy), a więc pośrednio liczbę ludności.

Niezwykle istotne jest prowadzenie równoległych badań z wykorzystaniem stanowisk o różnym potencjale. Jeziora i torfowiska mają zróżnicowany charakter, który wynika ze specyfiki środowiska akumulacji/ sedymentacji i może wpłynać na ciaggłość zapisu wydarzeń. Ponadto różne jeziora i torfowiska, choć teoretycznie podobne, mogą lepiej lub gorzej odzwierciedlać np. sygnał klimatyczny (choćby torfowisko Jaczno na Suwalszczyźnie) czy antropogeniczny (np. torfowisko Głęboczek w Borach Tucholskich ${ }^{85}$ ). Posiadanie komplementarnego zestawu danych zwiększa prawdopodobieństwo uzyskania ważnych informacji o wpływie człowieka na przyrodę, ale też klimatu na populacje ludzi.

Najważniejsze kwestie dotyczące integracji paleoekologii i geografii historycznej,

\footnotetext{
${ }^{85}$ M. Lamentowicz i in., Always on the tipping point - a search for signals of past societies and abrupt peatland ecosystem shifts during the last 6450 years in N Poland, "Quaternary Science Reviews", 225, 2019, 105954.
}

historii środowiskowej czy historii gospodarczej związane są z problematyką wpływu rozwoju osadnictwa i rolnictwa na przyrodę w ostatnim millennium, a także wpływu klimatu na działalność gospodarczą, również w kontekście rozwoju demograficznego ${ }^{86}$. Przeszłe epizody zmian klimatu, tj. ciepły okres średniowieczny lub mała epoka lodowa, miały w Polsce społeczne i ekonomiczne konsekwencje ${ }^{87}$, które wciąż czekają na pogłębione badania. Wpływ człowieka na środowisko również jest kwestią bezsporną, jednak pojawia się szereg pytań związanych z intensywnością i skalą działalności człowieka w przeszłości. Bardzo ważne jest uzyskanie odpowiedzi, jak zmiany użytkowania ziemi w czasach historycznych wpłynęły na obszary leśne, jak stopniowe otwieranie krajobrazu mogło wpłynąć na ekosystemy torfowisk i jezior ${ }^{88}$, a także jak historyczne zmiany środowiska wpłynęły na obecną strukturę użytkowania ziemi, wzorce społeczne i naturalne ekosystemy ${ }^{89}$.

Obecność i gospodarka człowieka w ostatnim millennium pozostawity wyraźne ślady w archiwach przyrodniczych, jakimi są torfowiska i jeziora. Wykorzystanie tych naturalnych dokumentów da ogromną szansę zrobienia kroku w kierunku zintegrowania geografii historycznej i paleoekologii w celu lepszego zrozumienia rozwoju ekonomicznego i często

\footnotetext{
${ }^{86}$ F.M. Chambers, Climate change and human impact on the landscape. Studies in palaeoecology and environmental archaeology, London-New York 1993; U. Buntgen i in., 2500 years of European climate variability and human susceptibility, „Science”, 331 (6017), 2011, s. 578-582

${ }^{87} \mathrm{M}$. Gałka i in., Disentangling the drivers for the development of a Baltic bog during the Little Ice Age in northern Poland, „Quaternary International", 328-329, 2014, s. 323-337; J. Haldon i in., History, S. $3210-3218$.

${ }^{88}$ R.A. Dull, Evidence for forest clearance, agriculture, and human-induced erosion in Precolumbian El Salvador, „Annals of the Association of American Geographers", 97 (1), 2007, s. 127-141; M.C. Feller, Deforestation and nutrient loading to fresh waters, w: Biogeochemistry of inland waters. A derivative of Encyclopedia of Inland Waters, ed. G.E. Likens, Amsterdam 2009, s. 587-600; D. Łuców i in., An impact of past catastrophic deforestations on the hydrology of Sphagnum peatland in Northern Poland, "Geophysical Research Abstracts”, 20, 2018.

${ }^{89}$ A.W.R. Seddon i in., Looking forward through the past, s. 256-267.
} 
bezpośrednio związanych z nim zmian ekosystemów Polski. Żeby uzyskać wysokiej jakości dane, potrzebujemy wyso- korozdzielczych wielowskaźnikowych rekonstrukcji pokazujących trendy zmian w przeszłości.

\section{Bibliografia}

Aaby B., Palaeoecological studies of mires, w: Handbook of Holocene palaeoecology and palaeohydrology, ed. B.E. Berglund, Chichester-Toronto 1986 , s. $145-163$.

Amesbury M.J., Barber K.E., Hughes P.D.M., The methodological basis for fine-resolution, multi-proxy reconstructions of ombrotrophic peat bog surface wetness, „Boreas”, 40 (1), 2011, s. 161-174.

Amesbury M.J., Swindles G.T., Bobrov A., Charman D.J., Holden J., Lamentowicz M., Mallon G., Mazei Y., Mitchell E.A.D., Payne R.J., Roland T.P., Turner T.E., Warner B.G., Development of a new pan-European testate amoeba transfer function for reconstructing peatland palaeohydrology, „Quaternary Science Reviews", 152, 2016, s. 132-151.

Aquino-López M.A., Blaauw M., Christen J.A., Sanderson N.K., Bayesian analysis of ${ }^{210} \mathrm{~Pb}$ dating, ,Journal of Agricultural, Biological and Environmental Statistics", 23 (3), 2018, s. 317-333.

Armstrong C.G., Shoemaker A.C., McKechnie I., Ekblom A., Szabó P., Lane P.J., McAlvay A.C., Boles O.J., Walshaw S., Petek N., Gibbons K.S., Quintana Morales E., Anderson E.N., Ibragimow A., Podruczny G., Vamosi J.C., Marks-Block T., LeCompte J.K., Awasis S., Nabess C., Sinclair P., Crumley C.L., Anthropological contributions to historical ecology. 50 questions, infinite prospects, „PLoS ONE", 12 (2), 2017, s. 1-26.

Badura M., Latałowa M., Szczatki makroskopowe roślin z obiektów archeologicznych Zespotu Przedbramia w Gdańsku, w: Zespót Przedbramia ul. Dtugiej $w$ Gdańsku. Studium archeologiczne, red. A. Pudło, Gdańsk 2016, s. 231-247.

Behre K.-E., The interpretation of anthopogenic indicators in pollen diagrams, „Pollen and Spores”, 23, 1981, s. 225-245.

Berggren G., Atlas of seeds and small fruits of Northwest-European plant species (Sweden, Norway, Denmark, East Fennoscandia and Iceland) with morphological descriptions, part 2: Cyperaceae, Stockholm 1994.

Berglund B.E., Ralska-Jasiewiczowa M., Pollen analysis and pollen diagrams, w: Handbook of Holocene palaeoecology and palaeohydrology, ed. B.E. Berglund, Chichester-Toronto 1986, s. 455-484.

Beug H.J., Leitfaden der Pollenbestimmung für Mitteleuropa und angrenzende Gebiete, München 2004.
Biagioni S., Krashevska V., Achnopha Y., Saad A., Sabiham S., Behling H., 8000 years of vegetation dynamics and environmental changes of a unique inland peat ecosystem of the Jambi Province in Central Sumatra, Indonesia, „Palaeogeography, Palaeoclimatology, Palaeoecology", 440, 2015, s. 813-829.

Biogeochemistry of inland waters. A derivative of Encyclopedia of Inland Waters, ed. G.E. Likens, Amsterdam 2009.

Birks H.H., The importance of plant macrofossils in the reconstruction of Lateglacial vegetation and climate. Examples from Scotland, western Norway, and Minnesota, USA, „Quaternary Science Reviews”, 22, 2003, s. 453-473.

Birks H.H., Plant macrofossils in Quaternary lake sediments, „Archiv für Hydrobiologie”, 15, 1980 , s. $1-60$.

Birks H.H., Birks H.J.B., Reconstructing Holocene climates from pollen and plant macrofossils, w: Global change in the Holocene, ed. A. Mackay, R.W. Battarbee, H.H. Birks, F. Oldfield, London 2003, s. 342-357.

Birks H.J.B., Birks H.H., Future uses of pollen analysis must include plant macrofossils, „Journal of Biogeography", 27, 2000, s. 31-35.

Birks H.J.B., Birks H.H., Quaternary palaeoecology, Baltimore 1980.

Blaauw M., Christen J.A., Flexible paleoclimate age-depth models using an autoregressive gamma process, „Bayesian Analysis”, 6 (3), 2011, s. 457-474.

Blaauw M., Christen J.A., Bennett K.D., Reimer P.J., Double the dates and go for Bayes. Impacts of model choice, dating density and quality on chronologies, „Quaternary Science Reviews”, 188, 2018, s. 58-66.

Blockley S., Candy I., Matthews I., Langdon P., Langdon C., Palmer A., Lincoln P., Abrook A., Taylor B., Conneller C., Bayliss A., MacLeod A., Deeprose L., Darvill C., Kearney R., Beavan N., Staff R., Bamforth M., Taylor M., Milner N., The resilience of postglacial hunter-gatherers to abrupt climate change, „Nat Ecol Evol”, 2 (5), 2018, s. 810-818.

Booth R.K., Ecology of testate amoebae (Protozoa) in two Lake Superior coastal wetlands. Implications for paleoecology and environmental monitoring, "Wetlands", 21 (4), 2001, s. 564-576.

Booth R.K., Testate amoebae as paleoindicators of surface-moisture changes on Michigan peatlands. Modern 
ecology and hydrological calibration, „Journal of Paleolimnology”, 28, 2002, s. 329-348.

Booth R.K., Jackson S.T., A high resolution record of late-Holocene moisture variability from a Michigan raised bog, USA, „The Holocene”, 13 (6), 2003, s. $863-876$.

Booth R.K., Lamentowicz M., Charman D.J., Preparation and analysis of testate amoebae in peatland paleoenvironmental studies, „Mires and Peat”, 7 (11), 2010, s. 1-7.

Brinkkemper O., Haaster H. van, Eggs of intestinal parasites whipworm (Trichuris) and mawworm (Ascaris). Non-pollen palynomorphs in archaeological samples, „Review of Palaeobotany and Palynology”, 186, 2012, s. 16-21.

Bronk Ramsey Ch., Deposition models for chronological records, „Quaternary Science Reviews”, 27 (1-2), 2008, s. 42-60.

Bronk Ramsey Ch., Development of the radiocarbon program OxCal, „Radiocarbon”, 43 (2A), 2001, s. 355-363.

Bronk Ramsey Ch., Radiocarbon calibration and analysis of stratigraphy. The OxCal program, „Radiocarbon”, 37 (2), 1995, s. 425-430.

Brown A., Badura M., King G., Gos K., Cerina A., Kalnina L., Pluskowski A., Plant macrofossil, pollen and invertebrate analysis of a mid-14 $4^{\text {th }}$ century cesspit from medieval Riga, Latvia (the eastern Baltic). Taphonomy and indicators of human diet, ,Journal of Archaeological Science. Reports", 11, 2017, s. 674-682.

Brown A., Banerjea R., Dawn-Wynne A., Stivrins N., Jarzebowski M., Shillto L.M., Pluskowski A., The ecological impact of conquest and colonization on a medieval frontier landscape. Combined palynological and geochemical analysis of lake sediments from Radzyn Chetminski, northern Poland, „Geoarchaeology”, 30, 2015, s. 511-527.

Brown A., Pluskowski A., Detecting the environmental impact of the Baltic Crusades on a late-medieval $\left(13^{\text {th }}-15^{\text {th }}\right.$ century) frontier landscape. Palynological analysis from Malbork Castle and hinterland, Northern Poland, „Journal of Archaeological Science”, 38 (8), 2011, s. 1957-1966.

Brown A., Pluskowski A., Medieval landscape transformation in the southeast and eastern Baltic. Palaeoenvironmental perspectives on the colonisation of frontier landscapes, „Archaeologia Baltica”, 20 (0), 2014.

Buckland P.C., Peatland archaeology. A conservation resource on the edge of extinction, „Biodiversity and Conservation", 2, 1993, s. 513-527.

Buntgen U., Tegel W., Nicolussi K., McCormick M., Frank D., Trouet V., Kaplan J.O., Herzig F., Heussner K.U., Wanner H., Luterbacher J., Esper J., 2500 years of European climate variability and human susceptibility, „Science”, 331 (6017), 2011, s. $578-582$.

Carcaillet C., A spatially precise study of Holocene fire history, climate and human impact within the Maurienne valley, North French Alps, "Journal of Ecology”, 86 (3), 1998, s. 384-396.

Chambers F.M., Climate change and human impact on the landscape. Studies in palaeoecology and environmental archaeology, London-New York 1993.

Charman D.J., Summer water deficit variability controls on peatland water-table changes. Implications for $\mathrm{Ho}$ locene palaeoclimate reconstructions, „The Holocene”, 17 (2), 2007, s. 217-227.

Charman D.J., Hendon D., Woodland W.A., The identification of testate amoebae (Protozoa: Rhizopoda) in peats. Technical guide No. 9, „Quaternary Science Reviews", 9 (9), 2000.

Chiverrell R.C., Innes J.B., Blackford J.J., Woodcock J.J., Davey P.J., Tomlinson P.R., Rutherford M.M., Thomas G.S.P., Palaeoecological and archaeological evidence for Bronze Age human activity on the Isle of Man, „The Holocene”, 14 (3), 2004, s. 346-360.

Clarke K.J., Guide to identification of soil Protozoa testate amoebae, "Soil Biodiversity Programme Research Report", 4, 2003, s. 1-40.

Cywa K., Trees and shrubs used in medieval Poland for making everyday objects, „Vegetation History and Archaeobotany”, 27 (1), 2018, s. 111-136.

Daniau A.L., Errico F. d', Sanchez Goni M.F., Testing the hypothesis of fire use for ecosystem management by neanderthal and upper palaeolithic modern human populations, „PLoS ONE”, 5 (2), 2010, e9157.

De Vleeschouwer F., Fagel N., Cheburkin A., Pazdur A., Sikorski J., Mattielli N., Renson V., Fialkiewicz B., Piotrowska N., Le Roux G., Anthropogenic impacts in North Poland over the last 1300 years. A record of $\mathrm{Pb}, \mathrm{Zn}, \mathrm{Cu}, \mathrm{Ni}$ and $\mathrm{S}$ in an ombrotrophic peat bog, „Science of the Total Environment”, 407 (21), 2009, s. 5674-5684.

Delcourt P.A., Delcourt H.R., Ison C.R., Sharp W.E., Gremillion K.J., Prehistoric human use of fire, the Eastern Agricultural Complex, and Appalachian oak-chestnut forests. Paleoecology of Cliff Palace Pond, Kentucky, „American Antiquity”, 63 (2), 1998, s. 263-278.

Dietze E., Theuerkauf M., Bloom K., Brauer A., Dörfler W., Feeser I., Feurdean A., Gedminienė L., Giesecke T., Jahns S., Karpińska-Kołaczek M., Kołaczek P., Lamentowicz M., Latałowa M., Marcisz K., Obremska M., Pędziszewska A., Poska A., Rehfeld K., Stančikaitė M., Stivrins N., Święta-Musznicka J., Szal M., Vassiljev J., Veski S., Wacnik A., Weisbrodt D., Wiethold J., Vannière B., Słowiński M., Holocene fire activity during low-natural flammability periods reveals scale-dependent cultural human-fire 
relationships in Europe, „Quaternary Science Reviews" 201, 2018, s. 44-56.

Dull R.A., Evidence for forest clearance, agriculture, and human-induced erosion in Precolumbian El Salvador, "Annals of the Association of American Geographers", 97 (1), 2007, s. 127-141.

Dzięgielewski K., The rise and fall of Biskupin and its counterparts, Warsaw 2017.

Feller M.C., Deforestation and nutrient loading to fresh waters, w: Biogeochemistry of inland waters. A derivative of Encyclopedia of Inland Waters, ed. G.E. Likens, Amsterdam 2009, s. 587-600.

Feurdean A., Galka M., Kuske E., Tantau I., Lamentowicz M., Florescu G., Liakka J., Hutchinson S.M., Mulch A., Hickler T., Last Millennium hydro-climate variability in Central-Eastern Europe (Northern Carpathians, Romania), „The Holocene”, 25 (7), 2015, s. 1179-1192.

Finsinger W., Schoning K., Hicks S., Lucke A., Goslar T., Wagner-Cremer F., Hyyppa H., Climate change during the past 1000 years. A high-temporal-resolution multiproxy record from a mire in northern Finland, „Journal of Quaternary Science”, 28 (2), 2013, s. 152-164.

Fire and climatic change in temperate ecosystems of the Western Americas, ed. T.T. Veblen, W.L. Baker, G. Montenegro, T.W. Swetnam, New York 2003.

Foissner W., Soil Protozoa: fundamental problems. Ecological significance, adaptations in ciliates and testaceans, bioindicators, and guide to literature, „Progress in Protistology", 2, 1987, s. 69-212.

French C.N., Moore P.D., Deforestation, cannabis cultivation and Schwingmoor formation at Cors Llyn (Llyn Mire), Central Wales, „New Phytologist”, 102 (3), 1986, s. 469-482.

Gałka M., Apolinarska K., Climate change, vegetation development, and lake level fluctuations in Lake Purwin (NE Poland) during the last $8600 \mathrm{cal}$. BP based on a high-resolution plant macrofossil record and stable isotope data ( $\delta 13 \mathrm{C}$ and $\delta 180)$, „Quaternary International”, 328-329, 2014, s. 213-225.

Gałka M., Aunina L., Tobolski K., Feurdean A., Development of rich fen on the SE Baltic coast, Latvia, during the last 7500 years, using paleoecological proxies. Implications for plant community development and paleoclimatic research, „Wetlands”, 36 (4), 2016, s. 689-703.

Gałka M., Miotk-Szpiganowicz G., Goslar T., Jęśko M., Knaap W.O. van der, Lamentowicz M., Palaeohydrology, fires and vegetation succession in the southern Baltic during the last 7500 years reconstructed from a raised bog based on multi-proxy data, „Palaeogeography, Palaeoclimatology, Palaeoecology”, 370, 2013, s. 209-221.

Gałka M., Tobolski K., Górska A., Milecka K., Fiałkiewicz-Kozieł B., Lamentowicz M., Disentangling the drivers for the development of a Baltic bog during the Little Ice Age in northern Poland, „Quaternary International", 328-329, 2014, s. 323-337.

Gearey B.R., Caseldine C.J., Archaeological applications of testate amoebae analyses. A case study from Derryville, Co. Tipperary, Ireland, „Journal of Archaeological Science”, 33 (1), 2005, s. 49-55.

Gearey B.R., Fletcher W., Fyfe R., Managing, valuing, and protecting heritage resources in the twenty-first century. Peatland archaeology, the ecosystem services framework, and the Kyoto protocol, "Conservation and Management of Archaeological Sites", 16 (3), 2014, s. 236-244.

Geel B. van, Non-pollen Palynomorphs, w: Tracking environmental change using lake sediments, vol. 3: Terrestrial, algal and siliceous indicators, ed. J.P. Smol, H.J.B. Birks, W.M. Last, Dordrecht-Boston-London 2002, s. 99-119.

Giesecke T., Davis B., Brewer S., Finsinger W., Wolters S., Blaauw M., Beaulieu J.-L. de, Binney H., Fyfe R.M., Gaillard M.J., Gil-Romera G., Knaap W.O. van der, Kuneš P., Kühl N., Leeuwen J.F.N. van, Leydet M., Lotter A.F., Ortu E., Semmler M., Bradshaw R.H.W., Towards mapping the late Quaternary vegetation change of Europe, ,Vegetation History and Archaeobotany”, 23 (1), 2013 , s. $75-86$.

Global change in the Holocene, ed. A. Mackay, R.W. Battarbee, H.H. Birks, F. Oldfield, London 2003.

Goodsite M.E., Rom W., Heinemeier J., Lange T., Ooi S., Appleby P.G., Shotyk W., Knapp W.O. van der, Lohse C., Hansen T.S., High-resolution AMS ${ }^{14} \mathrm{C}$ dating of post-bomb peat archives of atmospheric pollutants, „Radiocarbon”, 43 (2B), 2001, s. 495-515.

Goslar T., Ralska-Jasiewiczowa M., Geel B. van, Łącka B., Szeroczyńska K., Chróst L., Walanus A., Anthropogenic changes in the sediment composition of Lake Gościacz (central Poland), during the last 330 yrs, "Journal of Paleolimnology", 22, 1999, s. 171-185.

Gowen M., Casparie W., Caseldine C., Geary B., Hatton J., Stuijts I., Reilly E., Owens B., Murray C., Stevens P., Néill J.Ó., Cross S., Wetland and landscape archaeology in County Tipperary. The Lisheen Archaeological Project, 2000.

Grospietsch T., Wechseltierchen (Rhizopoden), Stuttgart 1958.

Grosse-Brauckmann G., Analysis of vegetative plant macrofossils, w: Handbook of Holocene palaeoecology and palaeohydrology, ed. B.E. Berglund, Chichester-Toronto 1986, s. 591-618.

Grosse-Brauckmann G., Einige allgemeine Ergebnisse von Torf-Großrestuntersuchungen, ,Telma”, 5, 1975, s. $39-42$.

Grosse-Brauckmann G., Streitz B., Über pflanzliche makrofossilien mitteleuropäischer Torfe. III. Früchte 
und Samen, Moose und einige Gewerbe (Fotos von fossilen Pflanzenresten), „Telma”, 22, 1992, s. 53-102.

Haldon J., Mordechai L., Newfield T.P., Chase A.F., Izdebski A., Guzowski P., Labuhn I., Roberts N., History meets palaeoscience. Consilience and collaboration in studying past societal responses to environmental change, „Proceedings of the National Academy of Sciences", 115 (13), 2018, s. 3210-3218.

Handbook of Holocene palaeoecology and palaeohydrology, ed. B.E. Berglund, Chichester-Toronto 1986.

Hölzer A., Die Torfmoose Südwestdeutschlands und der Nachbargebiete, Jena 2010.

Hughes P.D.M., Barber K.E., Mire development across the fen-bog transition on the Teifi floodplain at Tregaron Bog, Ceredigion, Wales, and a comparison with 13 other raised bogs, „Journal of Ecology”, 91 (2), 2003, s. 253-264.

The illustrated guide to the Protozoa, ed. J.J. Lee, G.F. Leedale, P. Bradbury, Lawrence 2001.

Izdebski A., Holmgren K., Weiberg E., Stocker S.R., Büntgen U., Florenzano A., Gogou A., Leroy S.A.G., Luterbacher J., Martrat B., Masi A., Mercuri A.M., Montagna P., Sadori L., Schneider A., Sicre M.-A., Triantaphyllou M., Xoplaki E., Realising consilience. How better communication between archaeologists, historians and natural scientists can transform the study of past climate change in the Mediterranean, „Quaternary Science Reviews”, 136, 2016, s. 5-22.

Janssens J.A., A quantitative method for stratigraphic analysis of bryophytes in Holocene peat, "Journal of Ecology", 71, 1983, s. 189-196.

Joosten H., De Klerk P., DAMOCLES. A DAshing MOnolith Cutter for fine sectioning of peats and sediments into LargE Slices, „Boreas”, 36, 2007, s. 76-81.

Kaal J., Carrión Marco Y., Asouti E., Martín Seijo M., Martínez Cortizas A., Costa Casáis M., Criado Boado F., Long-term deforestation in NW Spain. Linking the Holocene fire history to vegetation change and human activities, „Quaternary Science Reviews”, 30 (1-2), 2011, s. 161-175.

Kajukalo K., Fialkiewicz-Koziel B., Galka M., Kolaczek P., Lamentowicz M., Abrupt ecological changes in the last 800 years inferred from a mountainous bog using testate amoebae traits and multi-proxy data, „European Journal of Protistology”, 55, 2016, s. $165-180$.

Kamenik C., Knaap W.O. van der, Leeuwen J.F.N. van, Goslar T., Pollen/climate calibration based on a near-annual peat sequence from the Swiss Alps, ,Journal of Quaternary Science”, 24 (5), 2009, s. 529-546.

Kaplan J.O., Krumhardt K.M., Zimmermann N., The prehistoric and preindustrial deforestation of Europe, "Quaternary Science Reviews”, 28 (27-28), 2009, s. 3016-3034.

Kilian M.R., Plicht J. van der, Van Geel B., Dating raised bogs. New aspects of $A M S{ }^{14} \mathrm{C}$ wiggle matching, a reservoir effect and climatic change, "Quaternary Science Reviews", 14, 1995, s. 959-966.

Kittel P., Muzolf B., Płóciennik M., Elias S., Brooks S.J., Lutyńska M., Pawłowski D., Stachowicz-Rybka R., Wacnik A., Okupny D., Głąb Z., Mueller-Bieniek A., A multi-proxy reconstruction from Lutomiersk-Koziówki, Central Poland, in the context of early modern hemp and flax processing, "Journal of Archaeological Science", 50, 2014, s. 318-337.

Kittel P., Sikora J., Antczak O., Brooks S.J., Elias S., Krąpiec M., Luoto T.P., Borówka R.K., Okupny D., Pawłowski D., Płóciennik M., Rzodkiewicz, Stachowicz-Rybka R., Wacnik A., The palaeoecological development of the Late Medieval moat-Multiproxy research at Rozprza, Central Poland, „Quaternary International", 482, 2018, s. 131-156.

Kittel P., Sikora J., Wroniecki P., A Late Medieval motte-and-bailey settlement in a lowland river valley landscape of Central Poland, „Geoarchaeology”, 33 (5), 2018, s. 558-578.

Knaap W.O. van der, Lamentowicz M., Leeuwen J.F.N. van, Hangartner S., Leuenberger M., Mauquoy D., Goslar T., Mitchell E.A.D., Lamentowicz Ł., Kamenik C., A multi-proxy, high-resolution record of peatland development and its drivers during the last millennium from the subalpine Swiss Alps, „Quaternary Science Reviews”, 30 (23-24), 2011, s. 3467-3480.

Knaap W.O. van der, Leeuwen J.F.N. van, Climate-pollen relationships AD 1901-1996 in two small mires near the forest limit in the northern and central Swiss Alps, „The Holocene”, 13 (6), 2003, s. 809-828.

Kołaczek P., Gałka M., Lamentowicz M., Marcisz K., Kajukało-Drygalska K., Karpińska-Kołaczek M., Increased radiocarbon dating resolution of ombrotrophic peat profiles reveals periods of disturbance which were previously undetected, „Quaternary Geochronology”, 52, 2019, s. 21-28.

Kołaczek P., Karpińska-Kołaczek M., Madeja J., Kalinovych N., Szczepanek K., Gębica P., Harmata K., Interplay of climate-human-vegetation on the north-eastern edge of the Carpathians (Western Ukraine) between 7500 and 3500 calibrated years $B P$, „Biological Journal of the Linnean Society”, 119 (3), 2016, s. 609-629.

Kołaczek P., Zubek S., Błaszkowski J., Mleczko P., Margielewski W., Erosion or plant succession. How to interpret the presence of arbuscular mycorrhizal fungi (Glomeromycota) spores in pollen profiles collected from mires, „Review of Palaeobotany and Palynology”, 189, 2013, s. 29-37.

Kostrzewski J., Osada bagienna w Biskupinie w pow. żnińskim = Un village fortifiée sur le marais du premier âge du fer, découvert à Biskupin (Grande Pologne), „Przegląd Archeologiczny”, 5 (2-3), 1936, s. $121-140$. 
Kulczyński S., Torfowiska Polesia, t. 1, Kraków 1939 (Prace Rolniczo-Leśne, 37).

Kulczyński S., Torfowiska Polesia, t. 2, Kraków 1940 (Prace Rolniczo-Leśne, 37).

Lageras P., A commissioned archaeology in wetlands. Experience from the E4 project in Skane, Southern Sweden, „European Journal of Archaeology”, 6 (3), 2003, s. 231-249.

Laine J., Harju P., Timonen T., Laine A., Tuittila E.-S., Minkkinen K., Vasander H., The intricate beauty of Sphagnum mosses. A Finnish guide for identification, Helsinki 2009.

Lamentowicz M., Cedro A., Gałka M., Miotk-Szpiganowicz G., Mitchell E.A.D., Pawlyta J., Goslar T., Last millennium palaeoenvironmental changes from a Baltic bog (Poland) inferred from stable isotopes, pollen, plant macrofossils and testate amoebae, „Palaeogeography, Palaeoclimatology, Palaeoecology", 265, 2008, s. 93-106.

Lamentowicz M., Gałka M., Milecka K., Tobolski K., Lamentowicz Ł., Fiałkiewicz-Kozieł B., Blaauw M., A 1300 years multi-proxy, high-resolution record from a rich fen in northern Poland. Reconstructing hydrology, land-use and climate change, „Journal of Quarternary Science”, 28 (6), 2013, s. 582-594.

Lamentowicz M., Kołaczek P., Mauquoy D., Kittel P., Łokas E., Słowiński M., Jassey V.J.E., Niedziółka K., Kajukało-Drygalska K., Marcisz K., Always on the tipping point - a search for signals of past societies and abrupt peatland ecosystem shifts during the last 6450 years in N Poland, „Quaternary Science Reviews”, 225, 2019, 105954.

Lamentowicz M., Mitchell E.A.D., The ecology of testate amoebae (Protists) in Sphagnum in north-western Poland in relation to peatland ecology, „Microbial Ecology", 50 (1), 2005, s. 48-63.

Lamentowicz M., Obremska M., Mitchell E.A.D., Autogenic succession, land-use change, and climatic influences on the Holocene development of a kettle-hole mire in Northern Poland, „Review of Palaeobotany and Palynology”, 151 (1-2), 2008, s. 21-40.

Lamentowicz M., Tobolski K., Kowalewska G., Kowalewski G., $Z$ wody ląd, czyli jak z jezior powstaja torfowiska, w: Udostępnianie zasobów przyrodniczych Borów Tucholskich poprzez aktywna edukację ekologiczna. Materiaty na konferencję naukowa 21.11.2003, Charzykowy 2003, s. 106-113.

Lamentowicz M., Tobolski K., Mitchell E.A.D., Palaeoecological evidence for anthropogenic acidification of a kettle-hole peatland in northern Poland, „The Holocene", 17 (8), 2007, s. 1185-1196.

Landwehr J., Nieuwe atlas Nederlandse bladmossen, Zutphen 1984

Larocque-Tobler I., Grosjean M., Heiri O., Trachsel M., Kamenik C., Thousand years of climate change reconstructed from chironomid subfossils preserved in varved lake Silvaplana, Engadine, Switzerland, „Quaternary Science Reviews”, 29 (15-16), 2010, s. 1940-1949.

Latałowa M., Botanical analysis of a bundle of flax (Linum usitatissimum L.) from an early medieval site in northern Poland; a contribution to the history of flax cultivation and its field weeds, "Vegetation History and Archaeobotany", 7 (2), 1998, s. 97-107.

Latałowa M., Major aspects of the vegetational history in the eastern Baltic coastal zone of Poland (Lake Zarnowiec), „Acta Palaeobotanica”, 22 (1), 1982, s. $47-63$.

Latałowa M., Badura M., Jarosińska J., Archaeobotanical samples from non-specific urban contexts as a tool for reconstructing environmental conditions (examples from Elblag and Kotobrzeg, northern Poland), „Vegetation History and Archaeobotany”, 12 (2), 2003, s. 93-104.

Lityńska-Zając M., Wasylikowa K., Przewodnik do badań archeobotanicznych, Poznań 2005.

Loisel J., Yu Z., Surface vegetation patterning controls carbon accumulation in peatlands, „Geophysical Research Letters", 40 (20), 2013, s. 5508-5513.

Łuców D., Lamentowicz M., Kołaczek P., Łokas E., Lane C., Tjallingii R., Słowiński M., An impact of past catastrophic deforestations on the hydrology of Sphagnum peatland in Northern Poland, „Geophysical Research Abstracts", 20, 2018.

Magny M., Gauthier E., Vannière B., Peyron O., Palaeohydrological changes and humanimpact history over the last millennium recorded at Lake Joux in the Jura Mountains, Switzerland, „The Holocene”, 18 (2), 2008, s. 255-265.

Makohonienko M., Przyrodnicza historia Gniezna, Poznań-Bydgoszcz 2000 (Prace Zakładu Biogeografii i Paleoekologii).

Marcisz K., Gałka M., Pietrala P., Miotk-Szpiganowicz G., Obremska M., Tobolski K., Lamentowicz M., Synchronous fire activity and water table increases recorded from Sphagnum peatlands on the oceanic-continental climatic gradient, „Quaternary Science Reviews", 177 (C), 2017, s. 145-157.

Marcisz K., Lamentowicz M., Gałka M., Colombaroli D., Adolf C., Tinner W., Responses of vegetation and testate amoeba trait composition to fire disturbances in and around a bog in central European lowlands (northern Poland), „Quaternary Science Reviews", 208, 2019, s. 129-139.

Marcisz K., Tinner W., Colombaroli D., Kołaczek P., Słowiński M., Fiałkiewicz-Kozieł B., Łokas E., Lamentowicz M., Long-term hydrological dynamics and fire history during the last 2000 years in CE Europe reconstructed from a high-resolution peat archive, „Quaternary Science Reviews”, 112, 2015, s. 138-152.

Marcisz K., Vannière B., Blarquez O., Taking fire science and practice to the next level. Report from the 
PAGES Global Paleofire Working Group workshop 2017 in Montreal, Canada - paleofire knowledge for current and future ecosystem management, „Open Quaternary", 4, 2018.

Mauquoy D., Barber K.E., A replicated 3000 yr proxy-climate record from Coom Rigg Moss and Felecia Moss, the Border Mires, northern England, "Journal of Quarternary Science”, 14 (3), 1999, s. 263-275.

Mauquoy D., Geel B. van, Mire and peat macros, w: Encyclopedia of quaternary science, vol. 3: Pal-Pol, ed. S.A. Elias, Amsterdam 2007.

Mauquoy D., Geel B. van, Blaauw M., Plicht J. van der, Evidence from northwest European bogs shows 'Little Ice Age' climatic changes driven by variations in solar activity, ,"The Holocene”, 12 (1), 2002, s. 1-6.

Mauquoy D., Hughes P.D.M., Geel B.V., A protocol for plant macrofossil analysis of peat deposits, „Mires and Peat", 7, 2010, s. 1-5.

Mazei Y., Tsyganov A.N., Freshwater testate amoebae, Moscow 2006.

Meisterfeld R., Order Arcellinida, Kent 1880, w: The illustrated guide to the Protozoa, ed. J.J. Lee, G.F. Leedale, P. Bradbury, Lawrence 2001, s. 827-860.

Meisterfeld R., Testate amoebae with filopoda, w: The illustrated guide to the Protozoa, ed. J.J. Lee, G.F. Leedale, P. Bradbury, Lawrence 2001, s. 1054-1084.

Miola A., Tools for non-pollen palynomorphs (NPPs) analysis. A list of Quaternary NPP types and reference literature in English language (1972-2011), „Review of Palaeobotany and Palynology”, 186, 2012, s. 142-161.

Mitchell E.A.D., Charman D.J., Warner B.G., Testate amoebae analysis in ecological and paleoecological studies of wetlands. Past, present and future, „Biodiversity and Conservation", 17 (9), 2007, s. 2115-2137.

Mitchell E.A.D., Payne R., Testate amoeba analysis, „The Encyclopedia of Archaeological Sciences”, 2019, s. $1-4$.

Moore, P.D., Webb J.A., Collinson M.E., Pollen Analysis, Oxford 1991.

Ralska-Jasiewiczowa M., Goslar T., Madeyska T., Starkel L., Lake Gościaż, Central Poland. A monographic study, vol. 1, Kraków 1998.

Sadori L., Giraudi C., Masi A., Magny M., Ortu E., Zanchetta G., Izdebski A., Climate, environment and society in southern Italy during the last 2000 years. A review of the environmental, historical and archaeological evidence, "Quaternary Science Reviews", 136, 2016, s. 173-188.

Schmid B.V., Buntgen U., Easterday W.R., Ginzler C., Walloe L., Bramanti B., Stenseth N.C., Climate-driven introduction of the Black Death and successive plague reintroductions into Europe, „Proceedings of the National Academy of Sciences", 112 (10), 2015, s. 3020-3025.
Seddon A.W.R., Mackay A.W., Baker A.G., Birks H.J.B., Breman E., Buck C.E., Ellis E.C., Froyd C.A., Gill J.L., Gillson L., Johnson E.A., Jones V.J., Juggins S., Macias-Fauria M., Mills K., Morris J.L., Nogues-Bravo D., Punyasena S.W., Roland T.P., Tanentzap A.J., Willis K.J., Aberhan M., Asperen E.N. van, Austin W.E.N., Battarbee R.W., Bhagwat S., Belanger C.L., Bennett K.D., Birks H.H., Ramsey C.B., Brooks S.J., Bruyn M. de, Butler P.G., Chambers F.M., Clarke S.J., Davies A.L., Dearing J.A., Ezard T.H.G., Feurdean A., Flower R.J., Gell P., Hausmann S., Hogan E.J., Hopkins M.J., Jeffers E.S., Korhola A.A., Marchant R., Kiefer T., Lamentowicz M., Larocque-Tobler I., Lopez-Merino L., Liow L.H., McGowan S., Miller J.H., Montoya E., Morton O., Nogue S., Onoufriou C., Boush L.P., Rodriguez-Sanchez F., Rose N.L., Sayer C.D., Shaw H.E., Payne R., Simpson G., Sohar K., Whitehouse N.J., Williams J.W., Witkowski A., Looking forward through the past. Identifcation of 50 priority research questions in palaeoecology, "Journal of Ecology”, 102 (1), 2014, s. 256-267.

Sloan T.J., Payne R.J., Anderson A.R., Bain C., Chapman S., Cowie N., Gilbert P., Lindsay R., Mauquoy D., Newton A.J., Andersen R., Peatland afforestation in the UK and consequences for carbon storage, „Mires and Peat", 23, 2008.

Słowiński M., Lamentowicz M., Łuców D., Barabach J., Brykała D., Tyszkowski S., Pieńczewska A., Śnieszko Z., Dietze E., Jażdżewski K., Obremska M., Ott F., Brauer A., Marcisz K., Paleoecological and historical data as an important tool in ecosystem management, „Journal of Environmental Management”, 236, 2019, s. 755-768.

Smith A.J.E., The moss flora of Britain and Ireland, Cambridge 2004.

Swindles G.T., Plunkett G., Roe H.M., A multiproxy climate record from a raised bog in County Fermanagh, Northern Ireland. A critical examination of the link between bog surface wetness and solar variability, ,Journal of Quaternary Science”, 22 (7), 2007, s. 667-679.

Szafran B., Mchy, t. 1, Warszawa 1957.

Szafran B., Mchy, t. 2, Warszawa 1961.

Tinner W., Hu F.S., Size parameters, size-class distribution and area-number relationship of microscopic charcoal. Relevance for fire reconstruction, „The Holocene", 13 (4), 2003, s. 499-505.

Tobolski K., Przewodnik do oznaczania torfów i osadów jeziornych, Warszawa 2000.

Tobolski K., Torfowiska na przyktadzie Ziemi Świeckiej, Świecie 2003.

Tobolski K., Torfowiska Parku Narodowego „Bory Tucholskie", Charzykowy 2006.

Tracking environmental change using lake sediments, vol. 3: Terrestrial, algal and siliceous indicators, 
ed. J.P. Smol, H.J.B. Birks, W.M. Last, DordrechtBoston-London 2002.

Turner-Walker G., Peacock E.E., Preliminary results of bone diagenesis in Scandinavian bogs, „Palaeogeography, Palaeoclimatology, Palaeoecology”, 266, 2008, s. 151-159.

Tylmann W., Jeziorne osady rocznie laminowane w pótnocnej Polsce. Aktualny stan rozpoznania, postępy metodyczne i perspektywy badawcze, „Studia Limnologica et Telmatologica”, 5 (1), 2011, s. 23-41.

Tylmann W., Enters D., Kinder M., Moska P., Ohlendorf C., Poreba G., Zolitschka B., Multiple dating of varved sediments from Lake Lazduny, northern Poland. Toward an improved chronology for the last 150 years, „Quaternary Geochronology”, 15, 2013, s. 98-107.

Tylmann W., Zolitschka B., Enters D., Ohlendorf C., Laminated lake sediments in northeast Poland. Distribution, preconditions for formation and potential for paleoenvironmental investigation, „Journal of Paleolimnology", 50 (4), 2013, s. 487-503.

Udostęnianie zasobów przyrodniczych Borów Tucholskich poprzez aktywna edukacje ekologiczna. Materiaty na konferencję naukowa 21.11.2003, Charzykowy 2003.

Väliranta M., Blundell A., Charman D.J., Karofeld E., Korhola A., Sillasoo Ü., Tuittila E.S., Reconstructing peatland water tables using transfer functions for plant macrofossils and testate amoebae. A methodological comparison, „Quaternary International”, 268, 2012, s. $34-43$.

Walanus A., Goslar T., Datowanie Radioweglowe, Kraków 2009.

Walanus A., Goslar T., Wyznaczanie wieku metoda ${ }^{14} \mathrm{C}$ dla archeologów, Rzeszów 2004.

Warner B., Methods in Quaternary ecology, Montréal 1990 (Geoscience Canada Reprint, 5).

Weisbrodt D., Enters D., Żarczyński M.J., Poraj-Górska A.I., Tylmann W., Contribution of non-pollen palynomorphs to reconstructions of land-use changes and lake eutrophication. Case study from Lake Jaczno, northeastern Poland, „Limnological Review”, 16 (4), 2016, s. 247-256.

Wheeler J., Swindles G.T., Gearey B.R., Finding Bosworth battlefield. A multiproxy palaeoenvironmental investigation of lowland sediments from Dadlington,
Leicestershire, England, "Journal of Archaeological Science", 37 (7), 2010, s. 1579-1589.

Whitlock C., Anderson S.R., Fire history reconstructions based on sediment records from lakes and wetlands, $\mathrm{w}$ : Fire and climatic change in temperate ecosystems of the Western Americas, ed. T.T. Veblen, W.L. Baker, G. Montenegro, T.W. Swetnam, New York 2003, s. 3-31.

Whitlock C., Colombaroli D., Conedera M., Tinner W., Land-use history as a guide for forest conservation and management, "Conservation Biology”, 31 (1), 2017, s. 84-97.

Whitlock C., Larsen C., Charcoal as a fire proxy, $\mathrm{w}$ : Tracking environmental change using lake sediments, vol. 3: Terrestrial, algal and siliceous indicators, ed. J.P. Smol, H.J.B. Birks, W.M. Last, DordrechtBoston-London 2002, s. 75-97.

Wilkinson D.M., O’Regan H.J., Clare T., Where are the non-human bog bodies?, "Journal of Wetland Archaeology", 6 (1), 2006, s. 99-104.

Xoplaki E., Fleitmann D., Luterbacher J., Wagner S., Haldon J.F., Zorita E., Telelis I., Toreti A., Izdebski A., The Medieval climate anomaly and Byzantium. A review of the evidence on climatic fluctuations, economic performance and societal change, „Quaternary Science Reviews", 136, 2016, s. 229-252.

Yeloff D., Charman D., Geel B.V., Mauquoy D., Reconstruction of hydrology, vegetation and past climate change bogs using fungal microfossils, „Review of $\mathrm{Pa}-$ laeobotany and Palynology", 146, 2007, s. 102-145.

Zespót Przedbramia ul. Dtugiej w Gdańsku. Studium archeologiczne, red. A. Pudło, Gdańsk 2016.

Zolitschka B., Francus P., Ojala A.E.K., Schimmelmann A., Varves in lake sediments - a review, „Quaternary Science Reviews", 117, 2015, s. 1-41.

Zurek S., Związek procesu zatorfienia z elementami środowiska przyrodniczego wschodniej Polski, „Roczniki Nauk Rolniczych", 1990, s. 1-174.

Кац Н.Я., Кац С.В., Кипиани М.Г., Аmлас определитель плодов и семян встречаюшихся в четвертичньхх отложениях СССР, Москва 1965.

Кац Н.Я., Кац С.В., Скобеева Е.И., Аmлас растительных остатков в торфах, Москва 1977.

\section{The Importance of High-Resolution Multi-Proxy Paleoecological Research for Historical Geography and Economic History}

\section{Summary}

The article is a compact presentation of the importance of palaeoecology for historical research, with particular emphasis on economic history, historical geography, and environmental history.
The text presents methodological possibilities of palaeoecology, examples of works in this field and selected methods of paleoenvironmental reconstruction, such as the analyses of: pollen, 
non-pollen palynomorphs, plant macro-remnants, testate amoebae and charcoals. In addition, we draw attention to the unused potential of high-resolution palaeoecology in interdisciplinary studies of environmental changes in the field of historical geography. At the same time, we suggest what standard paleoecological data should have to be used in interdisciplinary studies implemented in various institutes around the world. Using natural archives, such as lakes and peatlands, we are able to trace the history of nature changes over long-time scales that go beyond the time scope of written sources in Poland. We remember, however, that the man who has always been part of nature has also left traces of his activity in these archives. By using them, and integrating paleoecological and historical sciences methods and tools, we can reconstruct this fascinating history and better understand the changes in Poland's ecosystems and the path of its economic development.

prof. dr hab. Mariusz Lamentowicz - kierownik Pracowni Ekologii i Monitoringu Mokradeł na Wydziale Nauk Geograficznych i Geologicznych UAM. Jego zainteresowania badawcze obejmują paleoekologię i ekologię mokradeł, zmiany klimatu oraz ochronę przyrody

(mariuszl@amu.edu.pl)

dr Monika Karpińska-Kołaczek - współpracuje z Pracownią Ekologii i Monitoringu Mokradeł na Wydziale Nauk Geograficznych i Geologicznych UAM. Jej zainteresowania badawcze obejmują zmiany zespołów palinomorf niepyłkowych i ameb skorupkowych w ciągu ostatnich dziesięciu tysięcy lat (monika_kk@interia.eu)

dr Piotr Guzowski - pracownik Centrum Badań Struktur Demograficznych i Gospodarczych Przednowoczesnej Europy Środkowo-Wschodniej Uniwersytetu w Białymstoku. Jego zainteresowania badawcze obejmują historię gospodarczą i demografię historyczną okresu preindustrialnego (guzowski@uwb.edu.pl)

dr Adam Izdebski - adiunkt w Instytucie Historii Uniwersytetu Jagiellońskiego, kierownik „Palaeo-Science \& History" Independent Research Group Max Planck Institute for the Science of Human History w Jenie. Jego zainteresowania badawcze koncentrują się wokół historii środowiskowej Bizancjum

(bydgostiensis@gmail.com)

mgr Sambor Czerwiński - doktorant w Pracowni Ekologii i Monitoringu Mokradeł na Wydziale Nauk Geograficznych i Geologicznych UAM. Jego zainteresowania naukowe obejmują paleoekologię, w szczególności rekonstrukcję roślinności, i wpływ człowieka w czasie holocenu

(sambor.czerwinski@amu.edu.pl)

dr Katarzyna Marcisz - adiunkt w Pracowni Ekologii i Monitoringu Mokradeł na Wydziale Nauk Geograficznych i Geologicznych UAM. Jej zainteresowania badawcze obejmują paleoekologię mokradeł, paleoekologię i ekologię ameb skorupkowych oraz wpływ zmian klimatu, pożarów i antropopresji na mokradła (marcisz@amu.edu.pl)

dr hab. Mariusz Gałka - profesor Uniwersytetu Łódzkiego, zatrudniony w Katedrze Geobotaniki i Ekologii Roślin na Wydziale Biologii i Ochrony Środowiska. Jego zainteresowania badawcze obejmują rekonstrukcje paleoekologiczne, m.in. rozwoju roślinności obszarów mokradeł (torfowisk, jezior, rzek) pod wpływem zmian klimatu, działalności człowieka i działalności wulkanicznej na terenie Europy, Azji, obu Ameryk oraz Afryki (mariusz.galka@biol.uni.lodz.pl) 
mgr Dominika Łuców - pracownik Zespołu Dynamiki Krajobrazów Minionych w Instytucie Geografii i Przestrzennego Zagospodarowania PAN, doktorantka na Wydziale Nauk Geograficznych i Geologicznych UAM. Jej zainteresowania badawcze obejmują paleoekologię i ekologię torfowisk, zaburzenia torfowisk, wpływ zmian klimatu na torfowiska oraz rekonstrukcje zmian środowiska przyrodniczego (dominika.lucow@twarda.pan.pl)

dr hab. Michał Słowiński - profesor Instytutu Geografii i Przestrzennego Zagospodarowania PAN, kierownik pracowni Dynamiki Minionych Krajobrazów. Paleoekolog, geograf, a przede wszystkim przyrodnik. Jego zainteresowania badawcze związane są z rekonstrukcją reakcji ekosystemów wodno-błotnych pod wpływem zmieniających się warunków klimatycznych oraz narastającej antropopresji

(michal.slowinski@geopan.torun.pl)

dr Piotr Kołaczek - adiunkt na Wydziale Nauk Geograficznych i Geologicznych UAM, specjalizujący się w analizie palinologicznej. Jego zainteresowania badawcze obejmują przemiany szaty roślinnej w kontekście zmian klimatycznych i działalności człowieka w ostatnich stu dwudziestu tysiącach lat (pkolacz@amu.edu.pl)

Mariusz Lamentowicz, Prof. Dr. hab. - head of the Laboratory of Wetland Ecology and Monitoring at the Faculty of Geographical and Geological Sciences, Adam Mickiewicz University in Poznań. His scholarly research interests cover palaeoecology and ecology of wetlands, climate changes and protection of nature (mariuszl@amu.edu.pl)

Monika Karpińska-Kołaczek, PhD - she collaborates with the Laboratory of Wetland Ecology and Monitoring at the Faculty of Geographical and Geological Sciences, Adam Mickiewicz University in Poznań. Her research interests include changes in non-pollen palynomorphs and testate amoebae throughout last 10,000 years (monika_kk@interia.eu)

Piotr Guzowski, PhD - employed at the Centre for the Study of Demographic and Economic Structures in Preindustrial Central and Eastern Europe, University of Białystok. His scholarly key interests include economic history and historical demography of preindustrial societies (guzowski@uwb.edu.pl)

Adam Izdebski, PhD - assistant professor at the Institute of History, Jagiellonian University in Kraków, head of the "Paleo-Science \& History" Independent Research Group Max Planck Institute for the Science of Human History in Jena. His research interests focus environmental history of Byzantium (bydgostiensis@gmail.com)

Sambor Czerwiński - PhD student at the Laboratory of Wetland Ecology and Monitoring at the Faculty of Geographical and Geological Sciences, Adam Mickiewicz University in Poznań. His scholarly interests include palaeoecology, in particular vegetation reconstruction and human influence during the Holocene (sambor.czerwinski@amu.edu.pl)

Katarzyna Marcisz, PhD - assistant professor at the Laboratory of Wetland Ecology and Monitoring at the Faculty of Geographical and Geological Sciences, Adam Mickiewicz University in Poznań. Her research interests focus on palaeoecology of wetlands, palaeoecology and ecology of testate amoebae, as well as impact of climate changes, fires, and anthropopressureon wetlands (marcisz@amu.edu.pl) 
Mariusz Gałka, Dr. hab. - associate professorof the University of Łódź, employed at the Department of Geobotany and Plant Ecology, Faculty of Biology and Environmental Protection, University of Łódź. His research interests focus on palaeoecologic reconstructions, i.a. vegetation succession in wetlands (bogs, lakes, rivers) vs climate change, human activity, and volcanic activity in Europe, Asia, North America, South America, and Africa

(mariusz.galka@biol.uni.lodz.pl)

Dominika Łuców, MSc - member of the Past Landscape Dynamic Laboratory at the Institute of Geography and Spatial Organization, Polish Academy of Sciences; PhD student at the Faculty of Geographical and Geological Sciences, Adam Mickiewicz University in Poznań. Her research interests include palaeoecology and ecology of peatbogs, peatbog disturbances, the impact of climate change on peat bogs and reconstructions of natural environment changes

(dominika.lucow@twarda.pan.pl)

Michał Słowiński, Dr. hab. - associate professor at the Institute of Geography and Spatial Organization, Polish Academy of Sciences, head of the Past Landscape Dynamic Laboratory. Palaeocologist, geographer, and above all naturalist. His research interests focus on reconstruction of natural environment changes occurring in lakes and peat bogs under the influence of changing climate conditions and increasing anthropopressure (michal.slowinski@geopan.torun.pl)

Piotr Kołaczek, PhD - member of the Faculty of Geographical and Geological Sciences, Adam Mickiewicz University in Poznań, specialising in palynological analysis. His scholarly interests include changes in plant vegetation in the context of climate change and human activity throughout last 120,000 years (pkolacz@amu.edu.pl) 